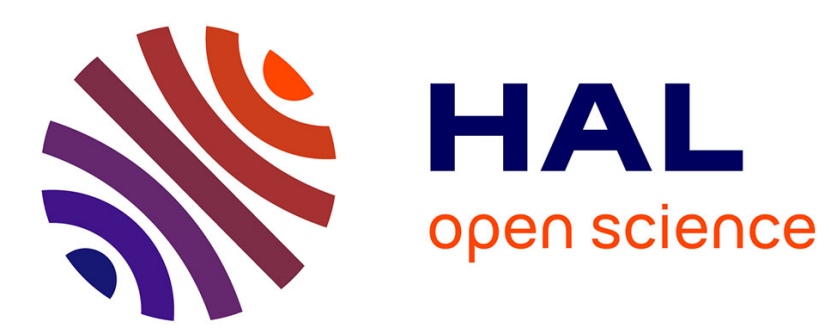

\title{
Managing the Downside of Active and Passive Strategies: Convexity and Fragilities
}

\author{
Raphaël Douady
}

\section{To cite this version:}

Raphaël Douady. Managing the Downside of Active and Passive Strategies: Convexity and Fragilities. Journal of portfolio management, 2019, 46 (1), pp.25-37. 10.3905/jpm.2019.1.112 . hal-02488589

\author{
HAL Id: hal-02488589 \\ https://hal.science/hal-02488589
}

Submitted on 23 Feb 2020

HAL is a multi-disciplinary open access archive for the deposit and dissemination of scientific research documents, whether they are published or not. The documents may come from teaching and research institutions in France or abroad, or from public or private research centers.
L'archive ouverte pluridisciplinaire HAL, est destinée au dépôt et à la diffusion de documents scientifiques de niveau recherche, publiés ou non, émanant des établissements d'enseignement et de recherche français ou étrangers, des laboratoires publics ou privés. 


\title{
Managing the Downside of Active and Passive Strategies: Convexity and Fragilities
}

\author{
Raphael Douady
}

University Paris 1-Pantheon-Sorbonne, CNRS and Labex ReFi

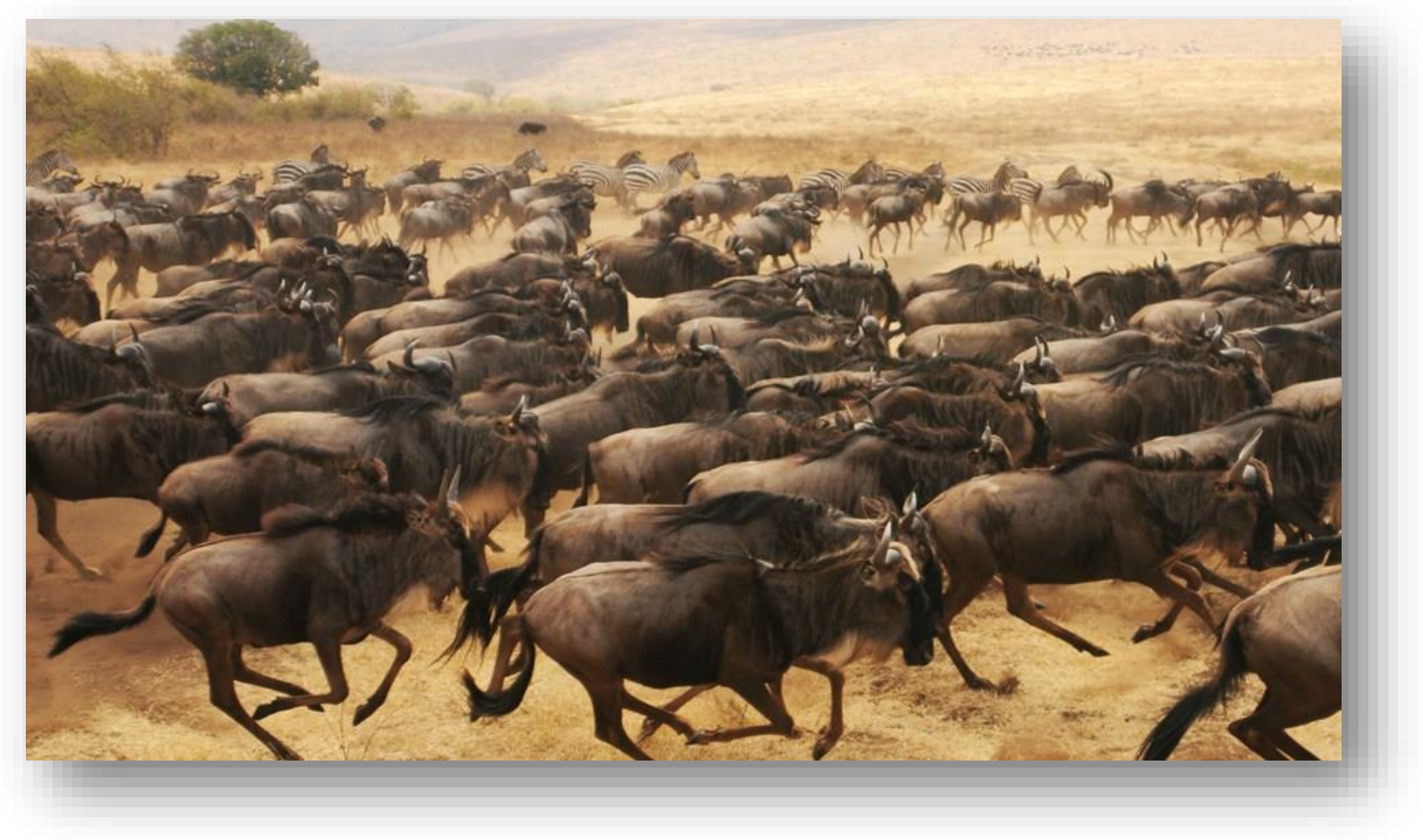

\section{Abstract}

Question of the day: how to manage a large (or small) portfolio in low interest rate conditions, while equity markets bear significant draw-down risk? More generally, how to build an "antifragile" portfolio that can weather the most extreme market scenarios without impacting long-term performances? Do active strategies systematically create or increase already existing market instabilities?

By analyzing in depth markets behavior during past speculative bubbles and credit crises, we aim at addressing these questions. Our goal is to describe as faithfully as possible the major mechanisms at stake, avoiding the trap of mapping the complexity of financial markets into a single mathematical model, which would necessarily be wrong at some point. Starting from Minsky's "Financial Instability Hypothesis", we try to disentangle the complex relation between dynamics and randomness, including the presence of "fat tails". We provide methods to monitor the evolving probability of a forthcoming crisis through the measurement of "market instability". Scalable investment strategies result from the application of these methods. 


\section{Table of Contents}

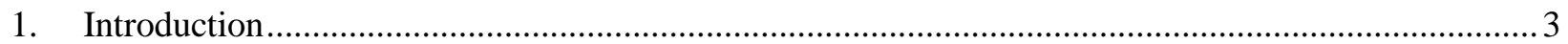

2. The Current Paradigm: Black-Litterman and Markowitz ...........................................................5

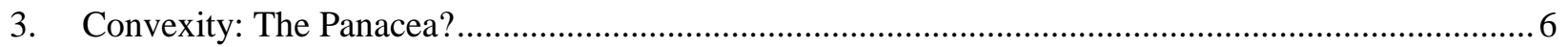

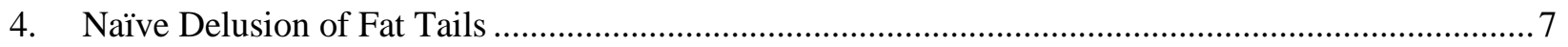

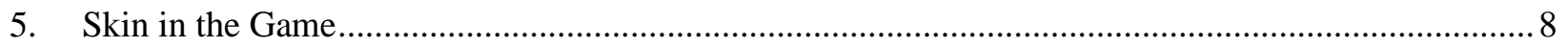

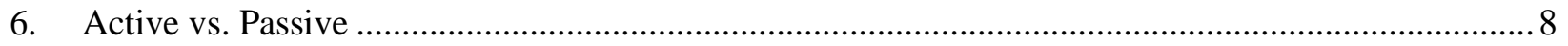

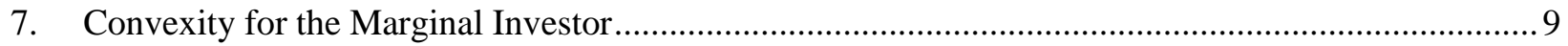

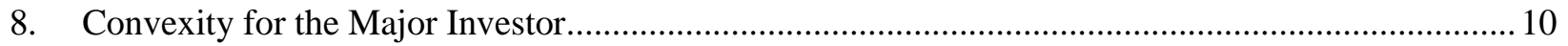

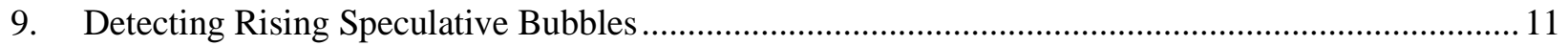

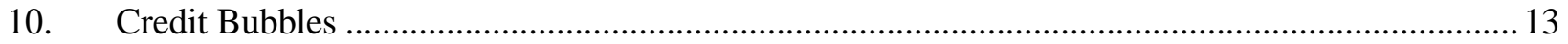

11. Market Instabilities: Predictable Dynamics vs. Pure Randomness ............................................. 14

12. Financial Crisis Indicators: Correlations and Dominant Factor Analysis................................... 16

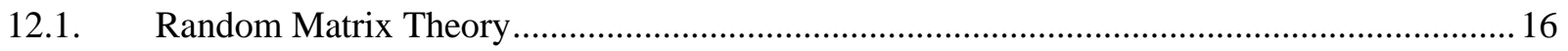

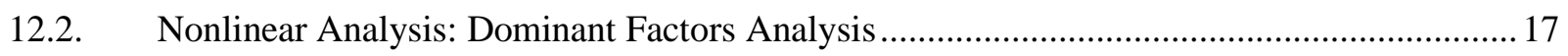

12.3. Regime Switching: Hidden Markov Model .......................................................................... 19

13. Downside risk management in portfolio management................................................................ 19

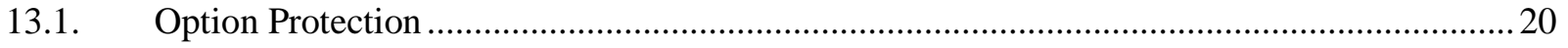

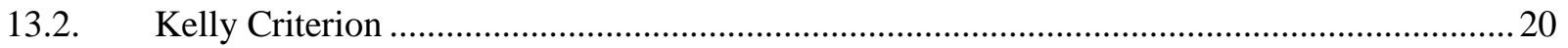

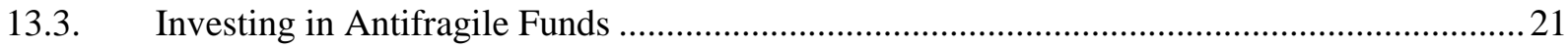

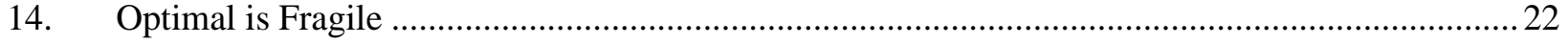

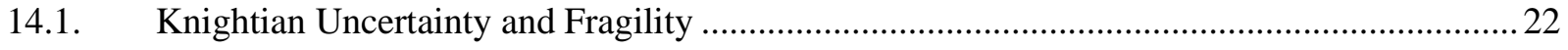

14.2. Multi-Regime Dynamics and Fat Tails ............................................................................. 23

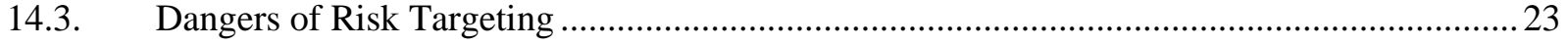

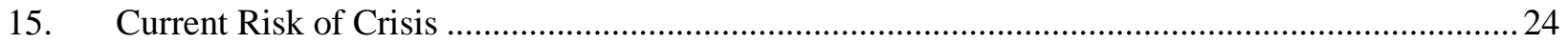

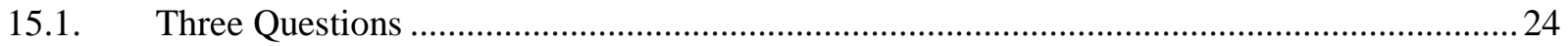

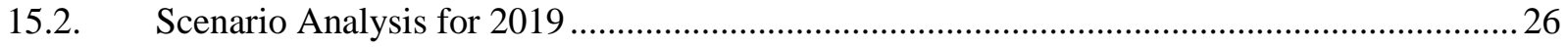

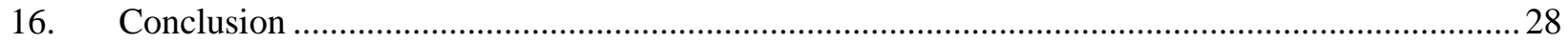

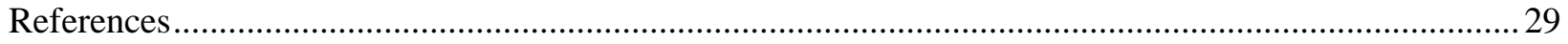




\section{Introduction}

Asset management today is facing a major dilemma. Fixed-income assets are delivering poor returns, as the interest rate yield, including those on corporate bonds, are at their historical lows. On the other hand, equity markets have experienced an unprecedented rally after bottoming out in 2009 after the financial crisis. With the VIX at its lowest level ever recorded before the correction that occurred at the beginning of February 2018, risk managers are justifiably asking themselves whether we are in a bubble and should fear a major crisis. Traditional concepts of risk reduction, "LDI" (Liability Driven Investment) and pure passive investing no longer apply. Institutional managers - pension funds, insurance companies, endowments, etc. - are caught between the hammer of a Black Swan drop in valuation of the equity markets and the anvil of being unable to cover their liabilities with absolute certainty.

This article addresses the difficult question of downside protection in an uncertain environment, where most of the risk of equity markets is not so visible and where safe havens cannot contribute returns which come anywhere close to meeting institutional manager's liabilities.

For decades, following the CAPM paradigm introduced by Samuelson, Markowitz, Sharpe, et al., "risk", in asset allocation, has been identified with "volatility", that is, the standard deviation of returns. Despite warnings by Mandelbrot and others about the non-normal distribution of returns and the existence of "fat tails", the second moment of distributions was, and still is, mainly used as a measure of portfolio risk. Shy improvements aimed at more accurately capturing the downside risk, such as the Sortino Ratio using the "downside volatility", have been devised. In Basel II accords, the Regulators have adopted the "Value-atRisk" as a gauge of investment risk. If properly measured, VaR may indeed represent a significant improvement as it involves both the potential fat tails and the asymmetry between upside and downside. The difficulty lies in the "properly measured" assumption. In order to do so, one must first determine the meaning of a "proper measure", that is, determining when one VaR estimate is better than another. This leads to questioning not only the risk measure, but also its testing. Poorly designed testing procedures may guide the risk manager to select a wrong risk measure or adopt an erroneous estimation procedure.

Let us be a bit provocative and ask a five-year-old child how she would define the "risk" of an investment. Is she more likely to answer: "how much I may lose" or "the standard deviation of my returns" or even "the $99^{\text {th }}$ percentile of my potential losses over the next 10 days period"? This simple example demonstrates that many approaches to risk estimation miss a fundamental feature of how market dynamics impact portfolio returns and how negative returns may accumulate over time.

This question takes a very different shape, when we are in the position of an economist advising a large portion of the asset management industry as opposed to a "marginal" manager, with no macroeconomic impact. Like a surfer who must jump off the wave that carries him ${ }^{1}$ at the right moment, before it breaks on top of him, a "marginal" manager must keep eyes wide open, anticipate market drawdowns, apply active management and catch as much as possible of the upside without taking the risk of being caught in the fall during major downturns. When advising the whole of the asset management industry, or a

\footnotetext{
${ }^{1}$ People sensitive to gender equality will forgive me for not using the politically correct "him/her" or "(s)he". I find these useless and only distracting the reader from the meaning of the sentence he is reading. I hope readers will understand that my use of the masculine is simply following the "old fashioned" convention according to which masculine is used to express the neutral gender when it is about people and not animals.
} 
significant portion of it, the dynamics of market feedback cannot be ignored. We are no longer a surfer, but the manager of a fleet of tankers that create their own waves.

Everybody remembers what happened on October 1987 "Black Monday". Following Black-ScholesMerton theory of option replication, a couple of finance professors in California posited that it was possible for asset managers to catch only the upside of markets, while avoiding the downside, by replicating the payout of a Call option. So-called "Portfolio Insurance" was in fact a simple strategy, consisting of holding a proportion of equities in the portfolio corresponding to the hedge ratio - the "Delta" - of the option one is trying to replicate. In practice, that meant holding more and more equities when the market was moving up and selling the position progressively when it was going down.

When a correction occurred on October $19^{\text {th }}$, 1987, it was a bit larger than usual (Wikipedia, 2003). Market participants started to sell-off their positions, thus accelerating the downturn and leading to what still is the largest one day drop in the history of the S\&P500 index. One could regret the fact that, at that time, Hyman Minsky's understanding of market dynamics was essentially ignored. A strategy that was supposed to create convexity for asset managers led to the creation of the most brutal concave profiles ever. The cost for "holding a call", was not just its time-value (the "Theta" in Black-Scholes theory). The reality of macroeconomic effects meant that portfolio insurance was equivalent to "selling a put". This historical example must be permanently kept in mind when addressing the question of active vs. passive investment, and all the related questions about "smart beta" indices, "risk timing" and automatic strategies. None of these approaches should be a priori discarded, but they must be used with care, and with due consideration to the dynamic effects that they may create.

This article is organized as follows: Sect. 2 and 3 describe the classical investment paradigm - Markowitz and Black-Litterman optimization approaches, portfolio insurance, volatility target and their flaws when facing instabilities. Sect. 4 warns about misconceptions regarding the origin of fat tails, while Sect. 5 points out a conflict of incentives between managers and end investors. Sect. 6 to 8 address the question of convexity, whether is it seen from the marginal investor point of view, or from a major one (or group of) with inevitable feedback loop after any rebalancing of the portfolio. Sect. 9 to 11 aim at describing the mechanisms of speculative bubbles and financial crises. Sect. 12 and 13 propose techniques to monitor the risk of a forthcoming crisis and build robust investment strategies, focusing more on downside protection than on day-to-day volatility. Sect. 14 points out the fragility of optimization under an environment subject top regime change. Sect. 15 shows how to properly implement a multi-scenario portfolio analysis and its practical consequences, taking information until the end of 2018 for an investment in 2019. Section 14 concludes. 


\section{The Current Paradigm: Black-Litterman and Markowitz}

As of today, the vast majority of long-term asset management is performed within the Black-Litterman framework (Black \& Litterman, 1991). This framework places Markowitz mean-variance optimization question in the context of Bayesian statistics.

In other words, while the goal is still to maximize a Sharpe ratio ${ }^{2}$ (Sharpe, 1966), the statistical estimation of the expected return, volatility and correlations of the portfolio components is incorporated in the optimization algorithm. The Bayesian approach provides both their estimate and the estimation uncertainty.

In order to perform Bayesian statistics, a "prior distribution" is required. If totally uninformed, BlackLitterman makes the a priori assumption that the main market index (e.g. the S\&P500 for US equities) is already optimized. Any departures from this assumption are known as "views" imposed by the manager. These "views" can be either data driven (observed statistics from historical time series of prices), or based on any kind of economic analysis, or a mix of both.

Contrary to a pure application of Markowitz's algorithm, which relies on the historical computation of variances and covariances of returns, Black-Litterman methodology is much more stable. A plot of historical correlations shows how unstable they are, sometimes ranging from $-100 \%$ to $+100 \%$, making Markowitz portfolios rather intractable in practice. On the contrary, as they incorporate statistical uncertainty, Black-Litterman portfolios are rather stable and "views" can be applied in quite an intuitive manner: should you expect a rise in a given sector, the portfolio will naturally overweight this sector, hence the popularity of the approach. And should you have no view at all, then the optimal portfolio becomes a simple passive one, following an index. This approach also fits well with a two-stage or more investment process: a strategic allocation between asset classes (equities, fixed income, etc.) and a tactical allocation into various sectors within particular assets.

However, nothing is simple when it comes to setting a framework which is meant to be used by the whole industry. The system, as a whole, reacts against itself and instabilities, as observed by Minsky ${ }^{3}$ (Minsky H. , 1992), will appear for any random reason. For example, if valuation of one sector starts rising, BlackLitterman "equilibrium" hypothesis will treat this price increase as "informed" and will recommend following it, therefore nurturing the rise, a dynamic which may evolve into a pure speculative bubble. This was recently observed on the US healthcare sector. The uptrend started slowly in 2011, accelerated in June 2014, and was eventually brutally reversed in August 2015 upon a general downturn caused by the seemingly unrelated burst of the Chinese equities bubble. Initially, in 2011, the overperformance of this sector with respect to the rest of the market was justified by its economic outcome. This rise mechanically attracted Black-Litterman-driven capital inflows that exaggerated healthcare's initial overpricing. At the downturn, this sector overreacted on the downside, eventually giving up all of its overperformance relative to the S\&P500.

\footnotetext{
${ }^{2}$ Sharpe ratio $=($ expected return - risk-free rate $) /$ volatility, all these features being measured on a yearly basis.

${ }^{3}$ Minsky's working paper was registered in 1992, however his observation of market instabilities as a source of economic cycles goes back to the late 50's.
} 


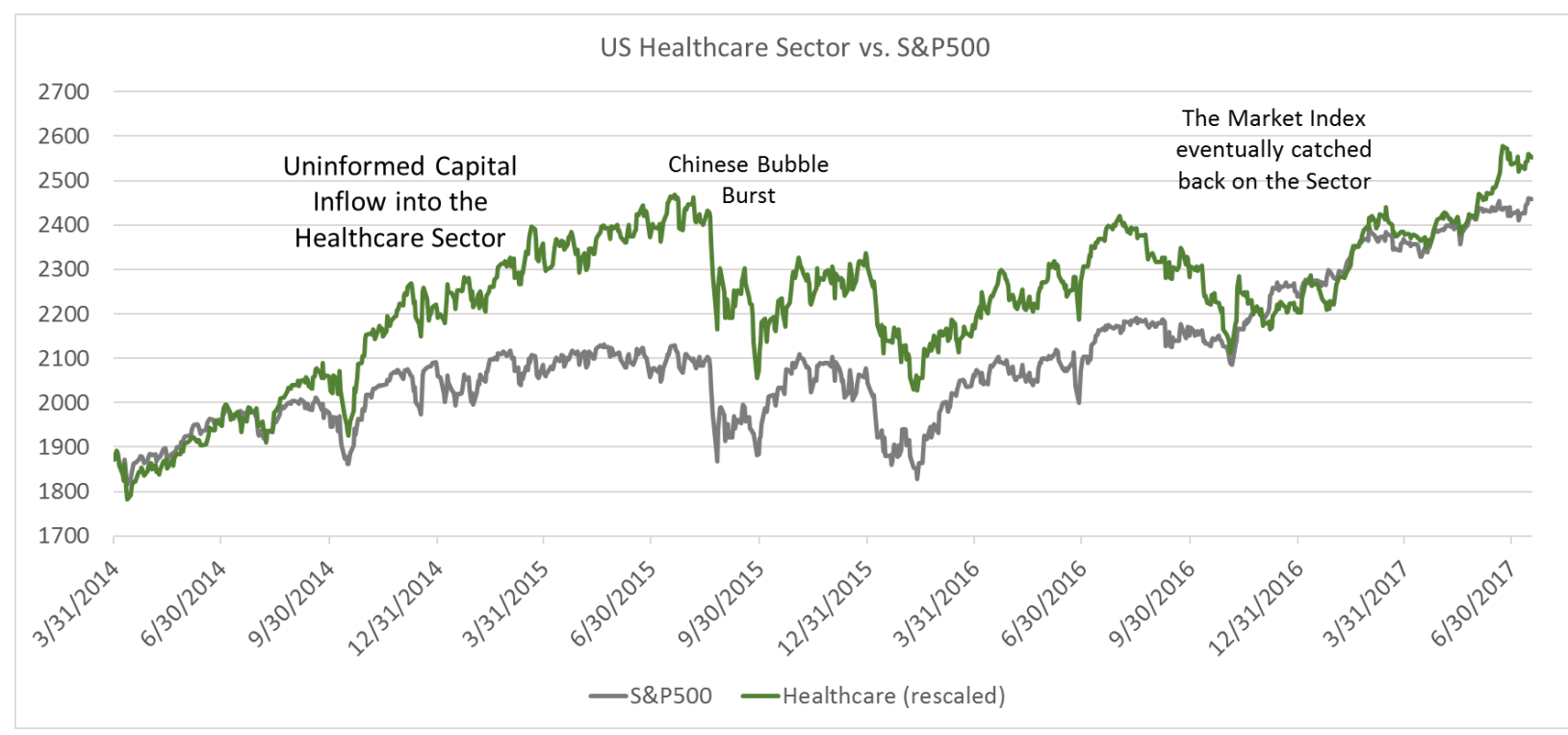

Figure 1

This example clearly demonstrates the weakness of the Black-Litterman approach. This asset allocation model relies on an equilibrium, yet not always true, hypothesis that "the market is always right" - an idea that has been the leitmotiv of several generations of economists on the Western side of the Atlantic Ocean which was unfortunately disproved by the facts, most recently by the 2008 financial crisis. While essentially based on mean-variance analysis, this model is exposed to regime changes and Black Swans. These not only destroy portfolio optimality when they occur, but trigger changes in market dynamics that have a durable impact on the investment performance.

\section{Convexity: The Panacea?}

The natural answer to this weakness of the Black-Litterman model is to apply some kind of active strategy which will dynamically compute the optimal asset allocation given the expected market evolution, instead of optimizing sector rotation and stock selection based on the views and historical statistics. When market outlook forecasts are expected to be favorable, the portfolio would be fully invested in the stock market. If proverbial clouds of a potential crisis appear on the horizon, portfolio derisking would be recommended. Such a strategy produces "positive Gamma", using option trading terminology, that is, an exposure to markets that is higher in up trends than in down trends.

Nothing is free: following the option trading metaphor, convexity produces excess return (one catches more of the upside than of the downside) but it does so at the expense of the "Theta" of the option, this is, its time value. In other words, one avoids a severe downside risk that occurs once in a while, but at the cost of an 'insurance premium' which leads to relatively inferior investment performance in the periods between the crisis. Overall, the long-term performance it not so much improved, but the path is much smoother. At least, it seems to be...

On October 19, 1987, the S\&P500 index experienced what is still today its largest one-day close-to-close loss: more than $20 \%{ }^{4}$ The standard deviation of daily market returns is in the order of $1 \%$, so we are talking of a 20-sigma event. What happened? Again, the answer is dynamic instability. In the spirit of the

\footnotetext{
${ }^{4}$ See footnote 2
} 
Black-Scholes-Merton option replication model, Hayne Leland and Mark Rubinstein (Rubinstein \& Leyland, 1981) devised an investment strategy, which they called "portfolio insurance", according to which one would maintain a position in equity markets that corresponds to the "Delta" of a call option, thus replicating its pay-out: the market performance if it is positive, and no loss (other than the cost of the replicating strategy) if it is negative. What Leland and Rubinstein failed to anticipate was the feedback loop between the market orders and its evolution. So long as the stock market stayed in the uptrend, participants increase their positions and reinforce the uptrend. But if markets start dropping, participants must start selling off their long positions, thus accelerating the fall in prices. This deadly dynamic occurred in the most volatile manner on that fateful day in October 1987.

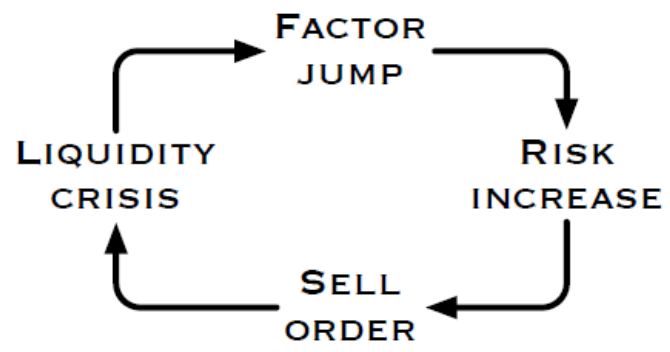

Figure 2

This tough experience was apparently not enough to demonstrate the danger of feedback loops in market dynamics. "Constant Proportion Portfolio Insurance" (CPPI) is a style of product that is still today proposed to investors. Such products experienced a second bad event in 2007 when, during the subprime crisis, several money-market funds that sought to enhance their performance with some proportion of CPPI investment "broke the buck", that is, displayed negative performances with fund unit prices dropping below $\$ 1.00$ (sometimes significantly, up to $-20 \%$ ). Certainly, after this second painful experience, CPPI funds are managed with much more care, with, for the best of them, rules preventing massive and blind sell-offs.

Summarizing these observations, we conclude that any attempts to replace Black Swans by a smoother evolution are fraught with danger. Not only one has to pay the insurance fee, but the sake for convexity creates its own Black Swans, that are no better than those they are supposed to avoid. In fact, we see that any given simple automatic rule to reduce fat tails on the downside produces its own potential severe losses. Efficient downside risk management requires more sophisticated approaches.

\section{Naïve Delusion of Fat Tails}

Fat-tailed models have been introduced in risk management to overcome the insufficiencies of popular "normal model", based on Gaussian distributions. But risk management is not simply risk measurement. The principle of distributional fat tails, for the purposes of VaR calculations, is to increase the probability of large events (e.g. 5 to 10 standard deviations) from something that is truly negligible to $1 \%$ or even higher.

However, this approach, based on stretching the shape of distributions in order to force them to incorporate observed occurrences that don't fit into the "normal" model, miss the essential of risk estimation, and therefore of its management: the actual behavior of markets during a crisis is far different from what can be observed in business as usual situations. Like a crowd in panic, rushing through the door when the fire alarm sounds, has nothing to do with the same crowd, calmly exiting the theatre at the 
end of the show. Yet, the panic behavior can be anticipated, not by "stretching" the normal orderly crowd scenario, but by observing the same or other crowds when they panic.

When financial markets enter a crisis, a certain number of well-known features are observed: different asset classes, which usually are uncorrelated, become correlated, while alternative investments, which have been precisely chosen for delivering alpha without beta, suddenly exhibit beta and no alpha at all, etc. Fat-tailed models, which are mostly calibrated on business-as-usual periods, completely miss these features of the crisis markets. So-called "robust calibration" is even more of a flawed approach to the problem, as it minimizes the weight of large events in the calibration, when one should, on the contrary, increase it.

The only possible approach to anticipate crises (even small ones) and provide meaningful hedging or risk mitigation recommendations is to use different models. Specifically, those models that, in order to simulate extreme events, deliberately focus on the most volatile periods and, more particularly, on the extreme correlations one can observe during these periods.

\section{Skin in the Game}

Everyone knows the story of the gentleman visiting Caiman Islands and being presented the harbor by a real estate agent: "Here is the broker's yacht, and here is the lawyer's yacht, and here is the administrator's yacht, and here the hedge fund manager's yacht...". After being presented all these beautiful ships, the gentleman naively asks: "Can you show me the investor's yacht?".

The answer lies in the analysis of the utility functions of everyone involved in the investment management production chain. The fund manager's fee structure, including the incentive, produces for him a convex utility function. As a consequence, his incentive is to maximize the extreme risk, to which he is less sensitive than the investor, and collect the corresponding extra performance fee. Put simply, the fund manager's convex utility function creates an incentive to have an investment portfolio with a concave profile. Other service providers are only exposed to the fund manager going out of business, while the investor is almost symmetrically exposed to gains and losses, with a bias for losses, due to the structure of the manager's fees if these contain performance fees.

Therefore, the investor's utility function is of utmost importance: He is by far the most exposed to downside risk.

One could expect the Regulator to impose "risk fairness" to the whole investment management production chain. Upon carefully reviewing Dodd-Frank, UCITS, MiFID Solvency II and other buy-side regulations, one is surprised to see the lack of Regulatory attention to the convexity question. One possible reason for this is the presence of the paradoxical effects described above. Faced with such ambiguity, Regulators perhaps found prudent to adopt a conservative attitude and only impose limits on managers' market exposure in its simple, linear approximation.

\section{Active vs. Passive}

The question of choosing between active and passive investment strategies needs to be approached very differently, whether one represents a marginal investor, acting on the side of the market with limited impact on it, or whether one is recommending a general strategy to be applied by a large chunk of the 
investment community, with corresponding dynamics and feedback effects. A solution like "portfolio insurance" that is good at the marginal level may become catastrophic if applied globally ${ }^{5}$.

For a marginal investor, an active strategy that anticipates major market downturns and cleverly selects sectors or securities to produce superior long-term returns while tempering the downside, makes a lot of sense. Marginal investors' main question is the quality of their market-risk prediction and security selection.

When advising the economy as a whole or acting as an investor or a group of investors controlling a significant portion of the market, one can't afford ignoring the economy as a whole and its dynamic behavior.

Many simple, automatic, active strategies are based on "reactivity": one tries to stick to the latest update of market statistics and invest accordingly. Consider, as an example, a Markowitz-optimized portfolio with a target level of volatility. As long as markets remain rather calm, such a portfolio overperforms a passive investment, both in terms of returns and of risks. However, upon major downturns, the loss from targeted volatility portfolio may exceed that of the market and offset years of over-performance. As explained earlier, when considering the feedback effect, such reactive strategies are even more damaging than a passive strategy.

In stark contrast, market anticipation strategies offer a number of advantages. Firstly, they provide "free convexity". While portfolio insurance reacts after the facts, implying that positions are reduced only after markets have dropped, and reinforced after they have risen, any anticipative strategy follows the market on the upside, while reducing exposure before the downturn. An obvious objection to the anticipative strategy is that no one has a crystal ball and can predict the markets. Not exactly true: the power of anticipation on long-term returns is so huge, that capturing even a relatively small portion of forthcoming moves produces appreciable benefits to portfolio returns. A pure mechanical dynamic strategy, which makes no specific assumptions on the market behavior, can provide partial downside protection for a marginal investor. One will still need to verify that the strategy is really robust to actual crises. However, anticipation is the only solution when markets as a whole, including feed-back, are considered. We should be extremely careful when an investment approach based on a mechanical action is generalized as these tend to produce a counter-effect that is prone to blow up in investors' face.

A second, less obvious, benefit of anticipation relies precisely on its difficulty. Every market actor uses a different, imperfect method, and actions come at different times. These heterogenous decisions dilute any potential market impact and thus help avoid, or at least reduce, the feed-back loop stemming from coincidental actions.

\section{Convexity for the Marginal Investor}

For marginal investors, the macroeconomic impact of whom on global markets can be neglected (which doesn't mean that one should ignore potential slippage and liquidity issues), the guiding principle is well explained in Taleb's "Black Swan" philosophy (Taleb, Black Swan, 2000): "prepare for the unexpected

\footnotetext{
5 We would like to vigorously combat the "market is always right" ideology that has prevailed for decades. We observe exaggeration and "exuberance" both ways - up and down - on a regular basis. But even more dramatic is the strong rejection of a certain school of economists, including many Nobel laureates, for anything that relates to market dynamics, feedback loops and the non-convergence of prices towards equilibrium. Convergence to equilibrium, which can be proved mathematically wrong, has been erected as an undiscussable axiom, leading to the catastrophes we know, in particular 1987 Black Monday and the way more damaging 2008 financial crisis.
} 
rather than try to predict it". In other words, put yourself in a position which, under no specific action of yours, will not lethally hurt you should a "Black Swan" event occur. Instead count on the fact that, upon such an "Black Swan" event, in practice, you may no longer be able to protect yourself. As a metaphor, you don't buckle your seatbelt when you see the accident coming, it's too late: you buckle up when you enter the car. ${ }^{6}$ Neither can you buy insurance when your house starts burning: no insurer would be foolish enough to provide you with an insurance policy at that time, unless its price is that of the whole house!

So, convexity is not an option. But its cost is a legitimate question. "Convexity" means a higher response to the upside than to the downside ("concavity" would be the opposite). In certain cases, "convexity" may even mean a positive response to both the upside and the downside. For instance, "momentum-" or "trend-following" strategies, often used by CTAs, have this property of being long in bull markets and short in bear markets.

Convexity can be achieved essentially in two ways:

1. Investing in securities that naturally have a convex response to market moves,

2. Dynamically adapting the exposure to market trends.

The first method involves, among others, option protection. Maintaining such a protection by buying put options may nonetheless be rather costly and severely impact performances. Selling call options to finance the protective puts is a possibility, but this strategy comes at a cost of giving up the "upward black swan", the role of which in the cumulative rates of long-term investment performances should not be underestimated.

The second method, as we have seen, can be disastrous if used in a reactive manner, that is wait for the downturn (or the upturn) to react. Adaptation must be anticipative. It is certainly easier said than done! As one says: "Prediction is a difficult art, especially when it's about the future..." We are not foolish enough to naively advise investors to "buy when the market is going to rise and sell when it's going to drop". However, given the contribution of Black Swans - one way or the other - to long-term performances, monitoring their probability of occurrence turns out to be extremely rewarding.

One can't pretend to predict when and where Black Swans will fall. However, detecting that markets are more prone to a Black Swan event is usually possible. We will show later the type of techniques that can be used for this purpose. The philosophy of it, rather than looking at the match or the cigarette that will set the forest ablaze, is to monitor the amount of dry wood and measure the hygrometry of the forest. We can't really tell when a spark will occur, but we can tell if this spark is likely to ignite the whole forest or not. When, for any reason, market participants are nervous, random fluctuations propagate and amplify much faster than when they are calm. One can't really tell what a fundamental price is and how far the current market prices are from it. A good telltale sign that we are away from it is investment managers' lack of comfort and overreaction to fluctuations, rather than to true information.

\section{Convexity for the Major Investor}

Major investors - large pension funds, sovereign funds, large institutions - cannot neglect the impact of their investment policy on financial markets. Even more so, since by applying a "policy", they tend to act as a herd as all of them apply the same or similar policies (e.g. Black-Litterman allocation model). Let us add to that the impact of regulations, which seem to underestimate, if not completely ignore, the so-called

${ }^{6}$ That looks quite an elementary observation but, if we think about it, "portfolio insurance" was no less, no more, proposing this strategy: "get out of the market when it falls..." 
"tragedy of the commons": that is, the fact that what looks good for one's safety can turn out to be devastating when applied to the whole community of investors, as we saw above. We shall come back to this point later.

Given the complexity of the question and the natural tendency of any active policy to create instabilities (e.g. "portfolio insurance" mentioned earlier), the first reaction of the investment community is to stick to a buy-and-hold strategy, that is, to simply track a cap-weighted stock index, revising the strategic allocation between stocks and bonds at an extremely low frequency, typically one or several years. We have seen, indeed, many large institutional asset managers congratulating themselves for not giving in to panic and staying invested after 2008 crisis, until markets rebounded in March 2009. This was quite the right thing to do after the crisis, once these managers got caught in it.

Any mid- and post-crisis active management would have - and did - aggravate(d) it. First, not all investors resisted the panic and many of them cut their positions at the worst moment. Second, large selloff orders, due to supposedly "sound" risk management policy, pushed markets further into the abyss. Such "sound" risk management policies were either pre-determined by the investment committees or, even, imposed by regulators through, for instance, Value-at-Risk limits. ${ }^{7}$

\section{Detecting Rising Speculative Bubbles}

As a matter of fact, most financial crises are endogenous, meaning that they are mostly due to a general unstable context - a speculative bubble or else - while the trigger is just a minor part of it. In the recent past, only 9/11 event, Kobe earthquake and Fukushima accident had a visible impact on markets. All other crises where just the collapse of a house of cards. So, the main question, for major investors, is to avoid the collapse and, if possible, to avoid building of the house of cards itself!

Again, easier to say than to do... Analyzing and understanding the dynamics of macroeconomics is a first step. At first, for good or bad reasons, after an informed economic analysis or a mere infatuation, some sector or macroeconomic area starts attracting capital. This phase is very important for the economy, as it is the core engine of value creation and innovation financing. Then comes a second phase, during which those who fear missing out start investing in masse, with less discernment than the first-phase investors. This is the start of the speculative bubble: money flows into less profitable investments, the capital value of which increases only because of the demand, but not because of their actual profitability. The musical chairs game begins, no one wants to miss the trend, investors buy assets not because they are attractive, but because they hope to be able to sell them at a higher price, or at least to mark them at high valuation. We all know the end of the story, when the music stops...

Though rather difficult, detecting the rise of a speculative bubble is of utmost importance. The graph below superimposes the histories of 2000 Tech Bubble Burst and 2015 Chinese Stock Market Crisis. Two different times, two different countries, and yet, a very similar pattern... The fact that start and peak levels were identical, so that we did not need any rescaling, was pure luck and doesn't deserve attention. Only shapes similarity and the phase sequence are of interest.

\footnotetext{
${ }^{7}$ I remember once an aircraft pilot telling about his old mother's prudence advice: "My son, be careful: fly low and slowly." One should take care of "common sense" prudence when complex dynamics are at stake.
} 


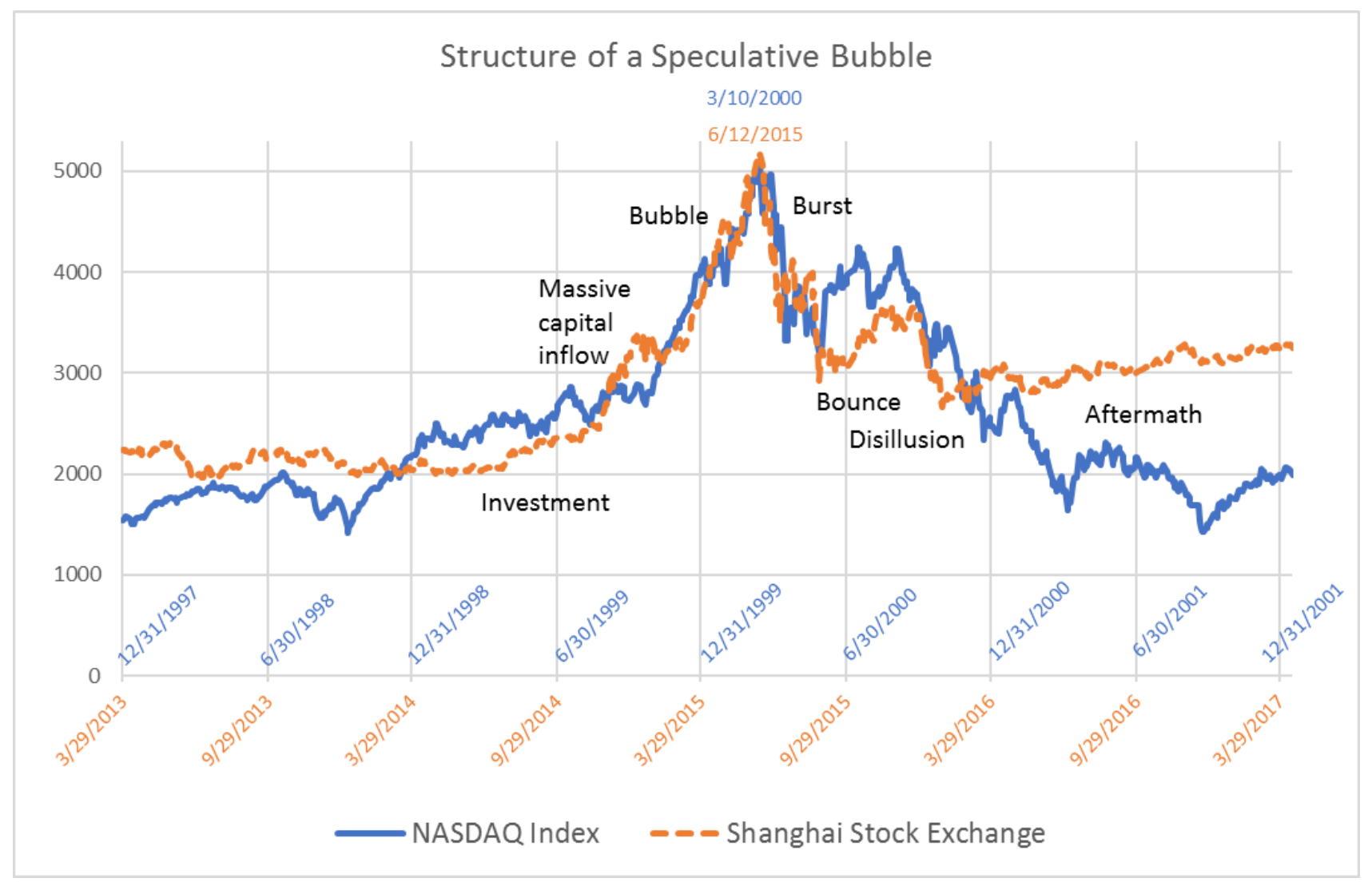

Figure 3

Sornette and Cauwells (Sornette \& Cauwells, 2015) identify speculative bubbles by the "superexponential growth" of prices, that is, the growth rate itself increases exponentially, leading to an explosion time due to "hyperbolic divergence" (without a burst, prices would grow to infinity in a finite time). As we can see in these two superimposed examples, the growth rate increases incrementally in phases, which correspond to investors' behavior. Whether continuously or incrementally, we see that the growth rate reaches unsustainable and unrealistic levels. Identifying the precise "hyperbolic" time is quite impossible, but identifying the emergence of a bubble early enough to stay safely away from it is possible. This will always drive regrets, as one cannot prevent from thinking that he should have stayed invested a bit longer. As Bernard Baruch used to say: "I made my money by selling too soon." ${ }^{8}$ Staying invested while the bubble is fully deployed is like playing Russian roulette. People doing so who pretend that they take "calculated risks" are lying to themselves to avoid confessing that they are just afraid of not following the herd.

Interesting patterns appear, both before the burst and after it. On the rising side, several corrections occur, with increasing size. A more accurate observation at the component of the index would reveal an asymmetric effect: while the rise is still a bit disordered, not all stocks moving up at the same pace, corrections are much more correlated, thus producing a nonlinear response of individual stocks to index moves. This concave pattern - like "selling a put" on the index - is a typical signature of markets nervousness. On the downturn, several bounces first occur, just days after the burst, when traders recover

\footnotetext{
${ }^{8}$ This quote is also sometimes attributed to J.P. Morgan or Nathan Rothschild. It is quite likely that all these people
} did pronounce this sentence or a similar one at some point in their life. 
from panic, then lose faith again, etc. following erratic news. At some point, "vultures" decide that it is time to buy and the true bounce phase occurs. What happens next depends on the particular context of each crisis and the new equilibrium the market is eventually finding in the aftermath.

In practice, the saying: "Buy on the cannons, sell on the trumpets" is all one needs to weather speculative bubbles and financial crises (and to trade in general). Yet, one needs to listen to markets sounds and avoid deafness, which precisely tends to occur when markets are very noisy with contradictory sounds.

\section{Credit Bubbles}

Credit bubbles are another sort of market disbalance, which should not be confused with speculative bubbles. While, in the latter, it is the equity valuation that derails, with the cost of money remaining rather sustained (short-term interest rates, inflation) even in the aftermath, to address investors' enthusiasm - not to say craziness - and the subsequent cash rarefaction, in credit bubbles, it is the leverage of companies that creates what is commonly known as "Minsky instability". ${ }^{5}$ Minsky distinguishes three types of borrowers: "hedge", "speculative" and "Ponzi". The "hedge borrower" has earnings in excess of the debt burden and can progressively reimburse the debt. The "speculative borrower" has earnings equal to the debt burden and maintains a constant level of debt. For the "Ponzi borrower", earnings don't meet the debt burden, and it must borrow more and more to face its installments, thus making the debt growing exponentially. The instability results from the fact that, in "blue sky" periods, interest rates are low, credit limits are loose and companies feel safe borrowing important amounts while staying in the "hedge" zone. But when, upon evolution of the economic cycle earnings decline, credit rationing occurs, the debt burden rises, and borrowers, once "hedged", migrate to the "speculative" and then to the "Ponzi" zones. This mechanics is in direct contradiction with the Modigliani-Miller "theorem", which, following some sort of microeconomic reasoning, states that the value of a company is, at optimum, independent of the split of its capital between equity and debt. The "proof" of this "theorem" makes the assumption that the borrowing rate is constant, an hypothesis that is precisely challenged by Minsky, and perhaps the reason why his research, which was already circulating in the late 1950's, was essentially ignored, and only rediscovered by the time of 2008 crisis.

Credit bubbles occur when the global leverage of the corporate sector as a whole, or of some particular industrial sector, increases in such a way that Minsky's mechanism is prone to take place at the systemic level upon a global decline in earnings and/or a rise in the cost of capital. For example, after the burst of the Tech Bubble in 2000, venture capital funds were eager to show some elements of return to compensate losses. The world of private equity was then living under the " $15 \%$ " diktat. In order to meet objectives, investors multiplied the LBO structures, mostly focusing on non-public companies, hence much less visible to statistics. This credit bubble came along with the real estate bubble and it was only a matter of months for it to blow up after the real estate bubble exploded in 2007. The default of Lehman Brothers in September 2008 was not the surprise. The surprise was that it took more than a year to happen!

Unlike a speculative bubble, where fat tails on the right-hand-side are, prior to the burst date, as important as they are on the left-hand-side after the burst, the returns statistics in a credit bubble are very asymmetric. Fat tails on the left-hand-side are present after the burst, but almost invisible on the righthand-side before the burst, because, even in favorable conditions, the price of debt securities remains bounded. Similar to a put-selling strategy that collects a penny every day and occasionally suffers dollarsize losses, a corporate debt portfolio in a credit bubble delivers the carry, plus some improvement as long as interest rates decline, but incurs major losses when defaults occur in cascade. 
It is no news that China's economy is experiencing a massive credit bubble that has lagged for a decade at least. However, within this credit bubble context, the 2015 crisis was a typical speculative bubble, generated by the massive inflow of foreign capital, following the "tunnel" law passed in the fall of 2014, allowing Hong Kong-based investors to redeem their profits realized on the Continent (namely Shanghai).

The following graph shows a comparison of 1998 Russian crisis with the major 2008 crisis. Here, we had to rescale not only the levels of the RTS index to match those of the S\&P500, but, working in a log-scale, we also had to rescale the log-returns of the indices, so as to account for the Beta $=3$ of the RTS vs. the S\&P500 (i.e. when the S\&P500 index doubles or is divided by 2, comparatively, the RTS index is multiplied or divided by $8=2^{\wedge} 3$ ). Interestingly enough, Russia - which also massively suffered from the 2008 crisis -, with its Beta of 3, seems to pave the near future of Western financial these days, with a similar 10 years period between the two crisis of 1998 and 2008, apparently translating into end of the "big rally" in February 2018.

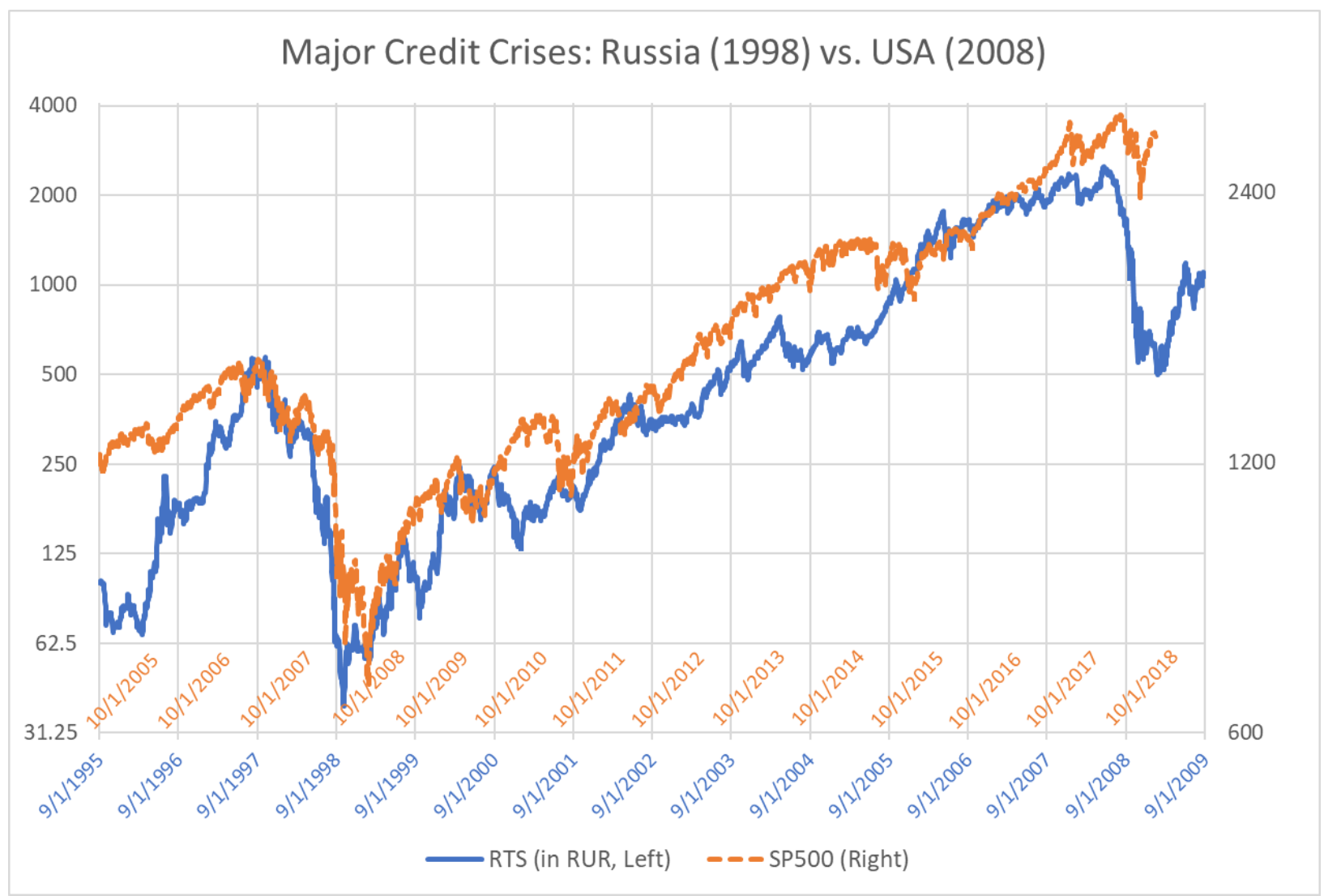

Figure 4

\section{Market Instabilities: Predictable Dynamics vs. Pure Randomness}

Peters's "Fractal Market Hypothesis" (FMH) (Peters, 1994) is an informal alternative to Fama's famous "Efficient Market Hypothesis" (EMH) (Fama, 1965), according to which, markets follow chaotic dynamics. In some sense, both hypotheses are wrong. The EMH is wrong because, like flat water doesn't exist in the ocean because it is physically unstable, ${ }^{9}$ prices are never at equilibrium, and speculative

\footnotetext{
9 This results from a well-known "Hopf bifurcation" - a concept from chaos theory - whereby a stable equilibrium breaks into a limit cycle. Water in a recipient, or even in a small pond, is at rest "flat and horizontal". But when the
} 
bubbles, whether big or small, are the normal state of capital markets. But the FMH is also wrong because it essentially misunderstands the basics of "chaos theory" which assumes deterministic, yet unpredictable, system evolution. Markets are way too complex to be deterministic, even in approximation. Nevertheless, one can say that a bubble occurs when the predictable part of market dynamics dominates their purely random component. Sornette and his collaborators built their research on financial crises on the intuitive idea that a crowd in panic is much more predictable than a calm one ${ }^{10}$, where everyone goes about their business in apparent randomness. They focus on the dynamical characteristics of crises. Those dynamic characteristics are extremely visible on the Bitcoin market, which one can see as some sort of "in vitro" experiment of a speculative bubble, with beautiful fractal structure. General financial markets are more complicated, because they are truly related to the real economy.

Market dynamics can be seen as a mix of predictable and purely random forces (a so-called random dynamical system). Most of the time, deterministic forces, which are driven by macroeconomics, are slow and completely invisible from the noise part. This validates the EMH, which assumes that markets are purely random. ${ }^{11}$ At crisis times, the deterministic component accelerates and becomes as fast as - not to say faster than - the random one. On the upside, volatility drops while the average returns are far away from flat ${ }^{12}$. While the exact moment of the burst is unpredictable, the cascade of effects that occur in the days and weeks that follow it has been thoroughly described by many authors (Kindleberger \& Aliber, 1978) (2015). The behavior of markets during both phases, taken separately, is rather foreseeable. The difficulty resides in the unpredictability of the burst moment, while in the up phase, and the impracticality of markets in the down phase. Downside risk management is therefore all about "how much too early" should one get out of the market before the bubble bursts.

Mathematically speaking, the word deterministic used in this paragraph, as opposed to random, technically means "set at the beginning of times", which means that the evolution equations are frozen. So-called "chaos theory" usually deals with such deterministic systems and states that, even though equations are fully known, the evolution of system bears some randomness, due to the exponential divergence of the accuracy: one would need an infinite accuracy at the beginning in order to be able to predict the state of the system in the future. In other words, while a unique and fully predictable evolution mathematically exists, it is not knowable in practice as the least tiny measurement error would, after some time, produce a completely different evolution.

When dealing with financial markets, nothing can be considered as mathematically "deterministic", because information is never complete, and the laws of evolution contain a substantial portion of randomness, even during a crisis when dynamics dominate. The "dynamical" part of the evolution should

size gets to that of a large lake, even more so with a sea or an ocean, this stable flat equilibrium breaks up and the "base motion" becomes the swell.

${ }^{10}$ I heard once, in a conference shortly after 2008 crisis, former Fed Reserve Governor Paul Volker questioning with force: "How mathematicians could pretend modeling a crowd in panic? This is impossible!" He couldn't be more wrong. Precisely, a panicking crowd is much easier to model than a disordered one. Economists who are, like him, strong believers in the EMH, are to be taken responsible for the crisis by obstinately rejecting any securities pricing model that would depart from it and from Arbitrage Pricing Theory.

11 Paul Samuelson was the biggest promoter of market dynamics as a random process driven by exogenous innovations, denying the existence of endogenous, in other words, dynamical forces. This ideology, not even unproven, but mathematically proven wrong, despite being supported by numerous academic articles in the most prestigious journals, played a disastrous role in the fold up of 2007-08 crisis, as it helped the industry stay in denial and leverage could grow without concerns during all the years preceding it.

12 In 2017, the Sharpe ratio of the SP500 index was 2.7, and even above 3 when including January 2018, historically unseen values, not surprisingly followed by a severe correction of $-10 \%$ during the first week of February. 
here be understood as the predictable part, that is, the average (next day) evolution, given current information, while the pure random part is the difference of the actually observed evolution to this predicted anticipation. Markets are unstable when simply compounding the predictable part of the evolution leads to a massive divergence, up or down, especially down! Feedback loops and investors' reactions to market evolution are of course part of the predictable component and should be accounted for when assessing market instability. These feedback loops are at the heart of Minsky's "Financial Instability Hypothesis" (FIH) (Minsky H. P., 1986). Minsky shows that instabilities are inevitable and inherent to capital markets, from the moment that one uses the marked-to-market accounting rule and that prices are determined by supply and demand. Hence it is not whether markets are stable or not, but how unstable they are and which level of protection one should maintain.

\section{Financial Crisis Indicators: Correlations and Dominant Factor}

\section{Analysis}

If we see markets as a gigantic random network of participants influencing each other, its instability comes from the overreaction of one to the other. That can mean orders passed by traders, but also the influence of an event in an asset class onto other asset classes (Khandani \& Lo, 2007) ${ }^{13}$. We present here some approaches to measure market instability and proneness to crises. These approaches are all based on the principle that increased internal reaction to shocks, hence high level of diffusion of information - too high, we would say - are the essential source of instabilities.

As explained earlier in this article, even a rather imprecise indication of a possible forthcoming crisis has very appreciable value for portfolio downside risk management, and therefore, for long-term returns. Unlike mechanical reactions to up and down moves of the market, which, when generalized, induce massive instabilities and a real crash risk, monitoring the degree of instability of the market leads to slow and mild corrections by portfolio managers with little global effect. Economic cycles won't - and can't be avoided, but, assuming that a significant portion of portfolio managers apply such "risk timing" strategies, they will occur in a softer manner, without brutal market downturns as we experienced in 2008.

\subsection{Random Matrix Theory}

Random Matrix Theory (RMT) predicts the distribution of a correlation or covariance matrix with random entries. Marchenko-Pastur theorem (Marchenko \& Pastur, 1967) provides the asymptotic distribution of eigenvalues, i.e. the weights in the Principal Component Analysis (PCA) of the covariance matrix computed from a large sample of independent variables with normal (i.e. Gaussian) distribution. The question becomes more complex when, instead of being independent, the variables are correlated, and even more when their distribution is not Gaussian, for instance when it has fat tails, as observed on market returns. However, empirical distributions can easily be obtained by simulations.

The idea to use RMT in crisis prediction (Douady \& Kornprobst, An Empirical Approach to Financial Crisis Indicators Based on Random Matrices, 2018) is to monitor unusual changes in the covariance matrix beyond its "natural" uncertainty, as predicted by the theory. Basically, in periods that precede crises, we witness regime instability: market nervousness tends to make the statistics of asset returns

\footnotetext{
13 On Aug 13, 2007, a few weeks after the subprime crisis that occurred in July 2007, a crisis occurred on the equity market, during which the most liquid stocks became extremely hard to sell, severely impacting long-short equity hedge funds. The reason was that multi-strategy hedge funds who were trading both fixed income and equities, had to respond to massive margin calls on their MBS portfolio and were constrained to liquidate large portions of the most liquid part of their equity portfolio, creating a liquidity crisis on what was considered the safest part of it.
} 
oscillate at a higher pace than usual between high and low volatility, as well as high and low correlations, together with an increased frequency of mid-size fat-tailed events. Consequently, the covariance matrix, computed on a rolling window, has unusual eigenvalues. The distance of its spectrum from that predicted by Marchenko-Pastur is an indicator of instability: the further away from the theoretical distribution, the more unstable the market and, consequently, the more probable a crisis in the near future. Even better is to monitor its distance to the empirical spectral distribution obtained with fat-tailed entries. In this case, on the contrary, the closer to this empirical distribution, the more unstable the market.

\subsection{Nonlinear Analysis: Dominant Factors Analysis}

Dominant Factor Analysis (DFA) is a powerful method using nonlinear polymodels to estimate the risk of an investment or a portfolio by examining its would-be behavior through numerous stress scenarios (Coste, Douady, \& Zovko, 2011), (Douady, 2017). Its principle consists in comparing the investment return to a very large number of potential risk factors, scanned and taken separately, by fitting a different nonlinear model for each factor. Unlike traditional multifactor models, which, to avoid overfitting, are constrained to be linear (i.e. with frozen correlations) hence not adapting to regime changes, nonlinear polymodels can incorporate regime changes within the model. Each factor is assigned a score corresponding to the quality of its fit with the investment. Only factors with a high enough a score are kept (so-called dominant factors), while other factors are discarded. For each dominant factor, fitting the investment to it provides an Impulse Response Function (IRF) which is then used to map crises experienced by the factor in the past to the current sensitivity of the investment to this risk factor. This systematic factor scanning produces a list of extreme scenarios for the investment which represent its Risk Profile. 


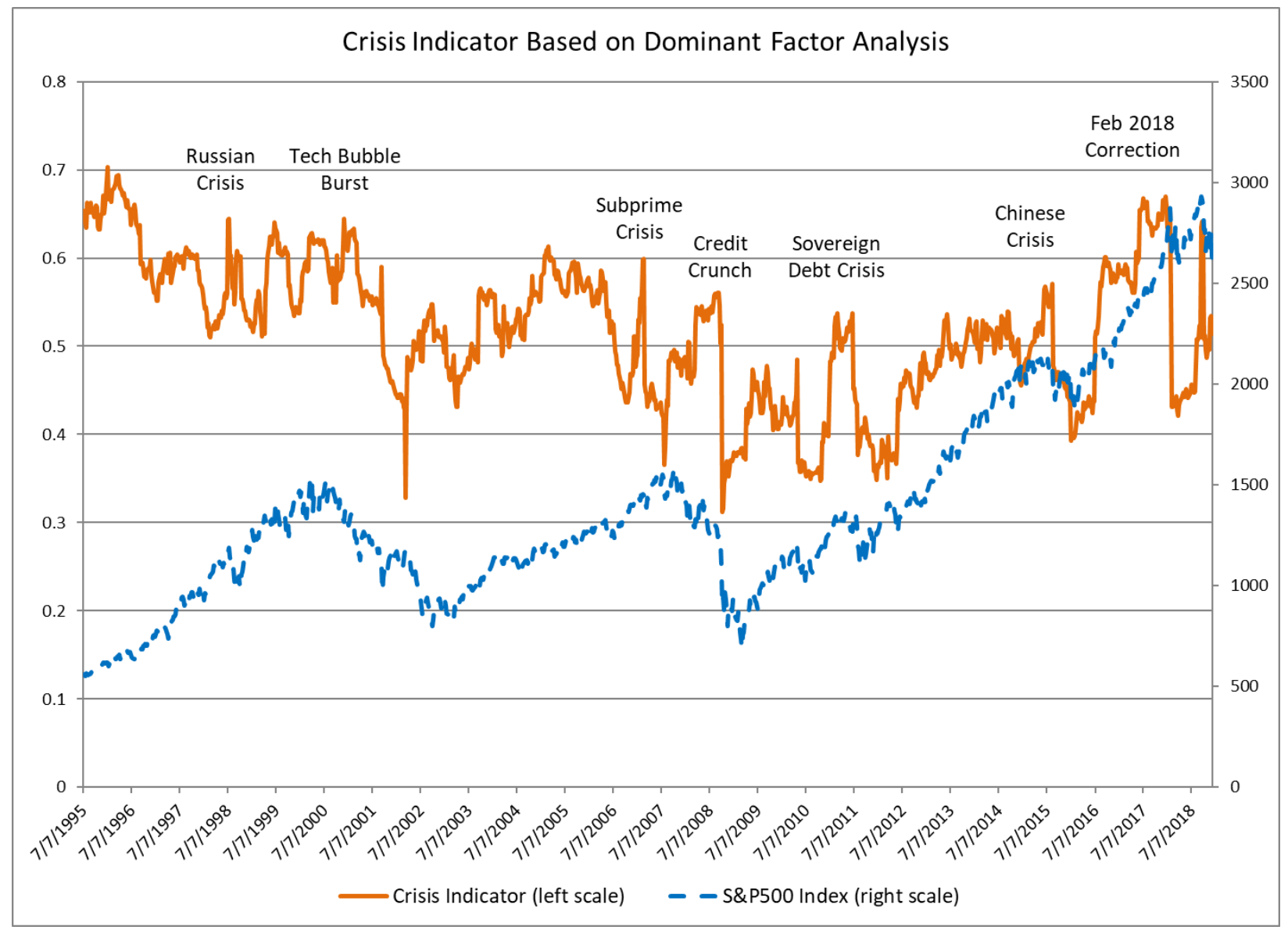

Figure 5

In periods preceding a financial crisis, the enhanced correlations between risk factors increase the number of dominant factors, hence of extreme scenarios that are mapped to the investment. Various crisis indicators can be derived from this information. One of them is simply the sum of scores of all the factors, an indicator that tends to "ring the bell" too often but doesn't miss a crisis (to use statistical testing language, its power is high, despite its large size.) (Douady \& Ye, 2019)

A second effect that reflects markets nervousness is the asymmetry between upside and downside reactions to "information". The reason for quotes on the word "information" is that it isn't necessary actual information, but what is perceived as such by market participants, that is, orders placed by other participants. In so-called "agent-based models", these are the reaction of "uninformed" traders to the actions of "informed" ones (Tefsatsion \& Judd, 2006) (Hommes, 2006). In real life, this separation is artificial, as no one knows, in a fully developed speculative bubble, what is true and what is fake information. Nevertheless, the closer we are to the burst of the bubble, the quicker and stronger the downside reactions and the more disordered the upside ones. We then observe an "inverse Anna Karenina" phenomenon ${ }^{14}$ : high downside and low upside correlations. As a consequence, indices become concave to each other. In a deterministic world, absent of randomness, if $y=f(x)$ with concave $f$, then $x=$ $f^{-1}(y)$ with convex inverse function $f^{-1}$. However, when both $x$ and $y$ are random variables with

\footnotetext{
${ }^{14}$ In reference to L. N. Tolstoy's Anna Karenina first sentence: “Happy families are all alike; every unhappy family
} is unhappy in its own way." In financial markets, stocks rally in their own way, while they tend to drop together. 
asymmetric upside and downside correlations, we can observe concavity both ways. Indeed, the beta is equal to the ratio of volatilities multiplied by the correlation, so, the upside beta of $y$ with respect to $x$ can be lower than the downside beta, while symmetrically, the downside beta of $x$ with respect to $y$ is also lower than the upside beta. This is exactly what happens in financial markets when ingoing into a speculative bubble when the upside correlations are significantly lower than the downside ones. Monitoring this asymmetry of upside and downside betas of various indices with respect to one another provides a strong indicator of forthcoming crises (work in progress.)

\subsection{Regime Switching: Hidden Markov Model}

Markets evolve through various statistical regimes, sometimes calmly and sometimes agitatedly, or, even in a dire crisis, with abrupt transition from one regime to another. A common approach to address this issue are the so-called GARCH models (Engle, 1982) (Bollerslev, 1986), in which the volatility (or the whole covariance matrix) stochastically evolves through time. While such models reproduce fat tails and the "volatility clustering" effect (periods of high and low volatility), they fail at producing abrupt changes, especially from calm to agitated periods, as we saw in February 2018, when the VIX jumped, in one day, from 7 to $40+$.

The "hidden Markov model" approach relies on a "hidden" feature, namely the parameters of a multivariate Gaussian distribution. Instead of a continuous (yet stochastic) evolution, drifts and covariances vary through time in a purely discontinuous manner, jumping from one value to another.

The base idea of a multi-regime hidden Markov process is that, at each time step, a regime is selected for the global market evolution. The return of each asset is a random realization of the distribution according to the selected regime.

The probability of choosing one regime or another depends, first, on the regime that was used in the previous step, and second, on a transition probability matrix between regimes. Each regime is represented by a multi-dimensional distribution, characterized by the drift of each asset and by their covariance matrix. Therefore, the aggregated distribution of returns across the regimes is a mixture of single-regime distributions. This produces commonly observed fat tails and black swan events, would a mild regime transit towards a wild one.

Regimes that are not necessarily very agitated but have a high probability of switching to a crisis regime will typically be considered as predictors of stormy weather.

The main difficulty of this approach is its calibration, that is, identifying regimes parameters (drift and covariances) and, even more so, the transition probabilities. From the pure statistical point of view, precrisis regimes are not so easy to distinguish from a period of durable calm. Machine learning methods, especially supervised learning, turn out to help in this regard.

\section{Downside risk management in portfolio management}

As this has been extensively explained throughout this article, "active downside protection" is possible but comes at a cost. This cost is not just the premium of the real or virtual put option one must buy or replicate. In the case of a group of investors representing a significant portion of the market, the hidden cost of active downside protection is the dynamic instability induced by the massively implemented automatic strategy, thereby justifying the quotes put on the words "active downside protection".

Effective downside protection can basically be achieved in three ways:

1. Buying protection with options or naturally contracyclical assets; 
2. Investing in assets or funds that naturally have a milder reaction to downtrends than to uptrends, i.e. "antifragile" assets;

3. Being more heavily invested in uptrend markets than in downtrend markets.

\subsection{Option Protection}

We have explained in several instances that the major mistake of 1987 theoreticians was to confuse 1 and 3 , arguing that an actual option and its replication through "dynamic hedging" were one and the same. When a liquidity crisis occurs, the actual type of security one holds matters the most: having to sell an asset in a plummeting market, or selling a European option, or simply exercising an American option are very different issues.

From the operational point of view, buying and rolling a put option is certainly the most efficient way to ensure a cap on the loss with respect to the last rolling date. This comes at a cost - the option premium which can severely impact long-term performances. In order to mitigate this impact, managers use a "covered-call" strategy, which consists in selling and rolling short a call option struck above the current index value at the rolling date. This is not fully satisfactory. Indeed, one compensates cutting downside tails by also cutting upside ones. This again comes at a cost, as an important part of the index profits resides in these exceptional rallies. Generally speaking, covered-call strategies don't have significantly higher long-term performances than their underlying index, but they certainly have less volatility and lower maximum drawdown.

If rolling options is a good solution from the operational point of view, to avoid liquidity traps at the downturn, it doesn't eliminate macroeconomic and systemic risks: quite the contrary. Despite common belief that speculation is a zero-sum game, by displacing capital to more or less value-creation areas of the economy, speculation does impact the global wealth. However, convexity is a zero-sum game. When one seeks convexity by buying an option, rather than by replicating it through an active investment strategy, with potential dynamic instability, that option is bought from a financial institution who is entitled to hedge it. The option convexity is not created out of the blue, it is simply bought from another institution, itself unable to create it out of the blue. This sell-side institution will, itself, pass it on to the "market" as a whole, thus creating the much-feared dynamic instability.

Once again, for the marginal investor, buying an option is a safe solution and the only remaining question is its price vs. the protection it provides. But the issue becomes very different when considering the investment community as a whole. Regulators' only answer to this difficult question resides in the "amount of economic capital": trying to ensure that each single institution has access to enough liquidity to face market downturns. Addressing the complex dynamics involving the buy-side, the sell-side, the underlying market and the option market, seems to be beyond consideration. Probably not an easy question, but given sums spent on carving, testing, drafting and enforcing financial regulations, research on the question of dynamic instabilities is, sadly enough, dramatically underfunded. The "market is always right" ideology certainly doesn't help raise interest in these matters.

\subsection{Kelly Criterion}

Kelly investment criterion aims at maximizing the logarithmic rate of return of an investment, by adjusting the amount invested as a function of the current wealth (Kelly, 1956). Kelly's formula provides an optimal size of a bet (with only two possible outcomes: win or lose) as a function of the current wealth. It states that the more we have accumulated wealth, the more we increase the next bet and, conversely, the smaller our wealth, e.g. following losses, the smaller our next bet. By maximizing the logarithm of the wealth, this formula forbids ruin, the logarithm of which would be negative infinity. For it to be applicable in practice, two conditions are required: the size of potential losses, relative to the that of the 
bet, must be limited and the bets can be made as small as desired. Note that this second condition is not fulfilled with illiquid investments, such as venture capital, project financing, private equity or alternative investments.

Unlike portfolio insurance, which relates market exposure to markets levels, which are an external information, Kelly criterion links the exposure to the performance of each individual investor, hence their actions are less prone to be jointly correlated than with portfolio insurance. Yet, a substantial market downturn that will conjointly reduce the wealth of all the large pension fund managers, while market volatility surges, is likely to induce a massive sell-off with the consequences we have described earlier.

To conclude, Kelly criterion produces the expected convexity (that of the exponential function), so long as investment supports and strategies of the various investors applying it are disjoint. A large overlap in their investment universe may create dynamic instabilities.

\subsection{Investing in Antifragile Funds}

Following N.N. Taleb's terminology, fragility refers to systems that suffer from environment volatility and changes, while antifragility refers to those who benefit from them (Taleb, Antifragile, 2012). Typically, systems whose response to stress is convex are antifragile, whereas those whose response is concave are fragile (Taleb \& Douady, 2013).

\subsubsection{Momentum Strategy}

A good example of an antifragile strategy is "trend following", also known as "momentum". This strategy, which is applied by a large part of managed futures accounts at Commodity Trading Advisors (CTA's) consists in following the "market trend", materialized by the difference between a short-term moving average (a few days/weeks) and a long-term one (several months). In up-trending markets, when the short-term average is higher than the long-term one, the strategy is long the future, and short in the opposite case of down-trending markets. ${ }^{15}$

Speculative bubbles are frequent in commodity markets. These strategies have all the characteristics of those we have described earlier and, consequently, create the same instabilities, which, when applied to future markets, potentially produce severe "backwardation", that is, when future prices are lower than spot ones (the opposite may occur as well, but is limited by "convenience yield" arbitrage).

\subsubsection{Naturally Convex Investments}

Aside from active strategies that, as we have understood, externalize concavity, rather than creating convexity ex-nihilo, some investments are naturally convex, even though their downside limit can be at an unbearably low level. This is for instance the case of small or micro-cap stocks, or even venture capital investments. For this kind of investment, the upside is rather unlimited (unicorns do exist!) while the most one can lose is the value of the investment (with caveats we will describe later). Such investments display a strong positive skew, due to their asymmetric risk profile. This positive skew is the signature of a convex response to major stock indices, which have a null or slightly negative skew. Other naturally convex investments include high dividend paying stocks, convertible bonds, project financing with reinvestment option, etc. (at variance, corporate bonds are naturally concave because they negatively

15 The principle of the strategy relies on the assumption that "informed trades", which typically are positively serially correlated (an up, resp. down, move is more likely to be followed by another up, resp. down, move), occur at a slower frequency than "information seeking trades", which typically are negatively serially correlated. Using moving averages erases the second kind of fast flipping trades, and only follows the first one, which are more consistent through time. 
respond to a drop in the value of their issuer, due to an increase of their credit spread, while the upside remains limited even if the issuer's stock performs very well.)

Mixing a positively skewed investment, even with high volatility and severe drawdown risk, with a very low risk one, such as cash or a monetary fund, produces a risk profile with the desired positive skew, while the downside cannot go lower than the cushion in cash or equivalent, the size of which can be adjusted so as to meet acceptable levels of risk in terms of volatility and maximum drawdown.

To summarize, a portfolio of large stocks, or one tracking an index of such, has a negative skew because of the "inverse Anna Karenina effect". On the contrary, a portfolio that mixes low risk (cash or monetary) with naturally convex investments (e.g. small or micro-cap stocks, etc.) keeps the positive skew while the level of risk can be monitored, for instance using Kelly criterion, by the size of the market exposure, that is, the amount invested in risky assets.

\section{Optimal is Fragile}

The vast majority of the literature on portfolio management is devoted to the sake of "optimal" investment. Hypotheses are made and tested on probabilistic representations of financial markets, models are calibrated on real data and optimal portfolios are derived from these tested and calibrated models. Everything looks sound, done with care and seriousness. This process is in fact deeply flawed and may lead to disasters. The flaw resides in model uncertainty and externalities. The optimization process itself creates, with high probability, a concave, i.e. fragile, exposure to model parameters and risk sources external to the model. Even more so, exposure to large events - so-called black swans - whether changes of parameters (or change of regime), or externalities, that is, model invalidation, is often increased by within model optimization. ${ }^{16}$

\subsection{Knightian Uncertainty and Fragility}

The base principle of optimization is to maximize some criterion: a utility function, a risk-adjusted expected return, a ratio between expected return and some risk measure, such as the Sharpe ratio for instance (Sharpe, 1966), (Markowitz, 1959) (1991). In all cases, the criterion depends on what Knight calls "risk" (Knight, 1921), namely, the random part of the probabilistic model of future returns. It ignores "Knightian uncertainty", that is, the randomness of future returns which is not part of the particular mathematical model in use: uncertainty on model parameters, externalities (risks not included in the model) and hidden risks, often non-quantifiable or hard to quantify. Optimization uses two kinds of inputs: model parameters, considered as given by a calibration process, and control variables, asset selection and weights in the case of portfolio optimization. It consists of finding the "best" values of the control variables, given the model and its parameters. By definition, if a set of values for the control variables maximizes a given criterion, the value of the criterion is, around that set of values, concave with respect to the control variables. Nothing prevents it from being, on the contrary, convex with respect to the parameters of the model, hence being antifragile to model error. However, most the time, the opposite happens, and the "optimal" portfolio is also concave (i.e. "fragile") with respect to model parameters, or at least to some of them. The usual answer to this issue is to allow a range of values for model parameters

\footnotetext{
${ }^{16}$ N.N Taleb often gives this example of flawed optimization: one needs to get as fast as possible from an apartment on the $6^{\text {th }}$ floor to the street for, say, catching a bus. The unoptimized solution is to rush to the staircase, with some existing risk of falling in the stairs and get hurt and significantly delayed. After optimization, only taking into account the start and end points, the speed and environment characteristics, such as gravitation, it is found that the fastest way from point A to point B is to jump through the window, with an increased probability of hitting an obstacle - now $100 \%$ - and an increased consequence - being killed instead of only hurt...
} 
that represents the uncertainty stemming from calibration error. The problem is that changes in parameter values are, most of the time, due to regime changes, not just to calibration error. Calibration error would be what one gets from a random process with stable statistics: primarily volatility and correlations, using estimators which didn't have enough time to converge. Changes of regime are much more violent: 10 to 20 times the calibration error, with volatility able to jump 5 folds in one day and correlations crossing the full interval from $-100 \%$ to $+100 \%$ in relatively short periods of time as well. Addressing the parameter uncertainty issue by allowing ranges instead of given values would only make sense if the ranges were wide enough, thus destroying all the information from past statistics.

\subsection{Multi-Regime Dynamics and Fat Tails}

Assume now that market statistics is represented by a superposition of several regimes, as in sect. 11.3, form the most probable to the most exceptional one. Typically, the most probable regime is a "blue sky" one, with limited volatility, reasonable correlations and no fat tails. Less probable ones are more extreme and correspond to one sort of crisis or another. Unless the recent past has been particularly agitated, it is much more probable that it will be statistically close to the "blue sky" regime. Any optimization process based on parameters calibrated on the recent past will tend on the one hand to maximize expected returns, which is only achievable by concentrating the selection on assets with high expected returns, also often associated with high risk. So, we have limited room there for optimization. It will, on the other hand, aim at minimizing the risk measure of the portfolio, based on a close-to-blue-sky statistics, in particular correlations. This is generally achieved by diversification, which highly depends on correlations. The "optimized" portfolio will have a well reduced risk under the first, blue sky, regime, but its risk under other regimes will not be reduced at all, if not just increased. This "optimized" portfolio therefore has, with high (but not full) probability, a rather reduced volatility or whatever risk measure in use, and with a low probability, a much higher volatility. In other words, the ratio of volatilities between the main "blue sky" regime and the other extreme ones, which is the exact definition of "fat tails", is significantly increased (often several-folds). In short, "optimization" ignoring the multiplicity of regimes produces fatter tails than they were initially.

\subsection{Dangers of Risk Targeting}

An economist once joked: "If you want less accidents, better have a sword coming out of the wheel than an airbag!" This reflects the adverse portfolio selection one may apply in case of false sense of security. Volatility targeting and, more generally, risk targeting (meaning any risk measure) is a common method for sizing the market exposure of a portfolio.

The first danger is measuring risk on the recent past. Market regimes don't change every day, so, in any back-test, statistics of the recent past are a good predictor of the near future, not in terms of trend, of course, but in terms of volatility. Therefore, at first glance, it seems good to use the recent past volatility to determine the amount of market exposure one is ready to accept. In periods of low volatility, one increases the exposure, and downsizes it when the volatility increases. In doing so, however, we can be brutally exposed to a sudden storm, as they often come on financial markets (the last one was during the first week of February 2018, during which the volatility was about five times what it was in January, after a sudden "correction" occurred). Indeed, whereas periods of high volatility usually take time to calm down, it is quite common that a period of low volatility, particularly when it comes together with a strong upside trend ("irrational exuberance"), suddenly after a downturn, breaks into a period of high volatility and negative trend. In practice, applying a "volatility target" strategy exposes the portfolio to losses in number of sigmas, which can be large if distributions are fat tailed - which truly is the case! (Mandelbrot, 1963) 
More importantly, monitoring the recent volatility of markets is rather easy and can be systematized (and is actually systematized in several "volatility target" ETFs). As such, in case of a downturn event as the one we experienced on Feb $2^{\text {nd }}, 2018$, all "volatility target" funds will deleverage at the same time, inducing massive sell-offs that destabilize the market. True trading may then be very different from backtests...

The second danger is that of optimization based on distributions calibrated on the past, ignoring regime changes. As we saw above, such optimization produces fatter distribution tails for the portfolio than for its constituents. Applying a volatility target strategy on such a portfolio exposes managers to an amplified impact of sudden regime changes. This impact, which is measured in number of sigmas (multiplied by the set volatility target) and not just in percentage change of constituent prices, is inversely proportional to the past volatility of the portfolio, which can be very low (hence a larger impact) if it is "optimized".

\section{Current Risk of Crisis ${ }^{17}$}

\subsection{Three Questions}

Over the 13 months period from January 2017 to the end of January 2018, the Sharpe ratio of the S\&P500 index exceeded 3, an extremely high and unsustainable value. Indeed, since the beginning of February 2018, the market became much more chaotic, volatility went up several-folds, while the performance was negative. Many today predict a massive catastrophe, worse, for some, than that of 2008, based on considerations of an over-priced market. However, while a large part of these Cassandras are simply reacting to their lack of anticipation in 2007-08, several scenarios are possible for the correction of an over-priced market. By themselves, excessive P/E ratios do not imply that the market will experience a severe crisis, notwithstanding the fact that 2019 and/or 2020 yearly performances can be significantly negative.

There are three different questions, which should be addressed with different methods:

- Are financial markets prone to a major crisis in the near future?

- What will be market volatility in the months/year to come?

- Will next year performance be positive or negative?

The three of them, nonetheless, come down to the same question: "how much should one be invested in equity markets?". Yet, they represent distinct issues, depending on the type of portfolio manager. That who must ensure liquidity at an unknown moment cannot afford important drawdowns, would recovery come later, whereas that who is driven by long-term results to meet liabilities is essentially concerned with the yearly performance. At variance, that whose asset under management is directly linked to the volatility of his portfolio must keep it as low as possible, while preserving performance.

The odds of a forthcoming crisis are related to the dynamic instability. Whether pre-programmed, behavioral or mechanical, driven by algorithms or regulations, if a price perturbation induces a reaction that amplifies this perturbation, markets are dynamically unstable and prone to a crisis. The most recent record of the crisis indicator based on Dominant Factor Analysis (Fig. 4) indeed raises concerns.

17 This paragraph was written on Dec 19, 2018. The correction that occurred since mid-September 2018 is also brutal, but not a surprise in terms of volatility, unlike that of February. 


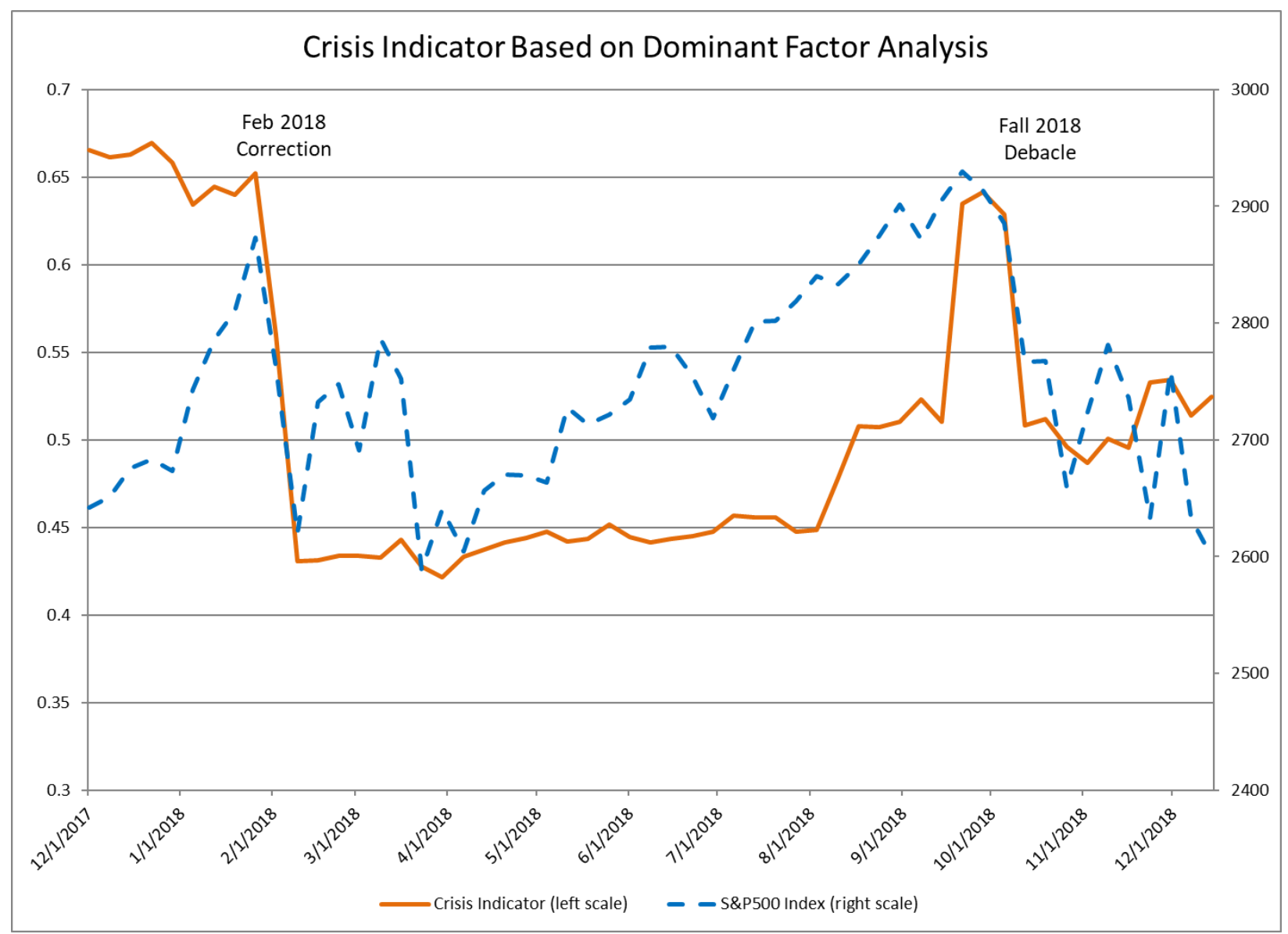

Figure 6

This indicator, which measures the degree of correlation within worldwide markets, peaked to 0.65 in December 2017 and January 2018, announcing the correction of February. It then dropped below 0.45 upon the correction and remained at this level during the bounce. It then peaked again slightly before the plunge that started at the end of September and fell again when the drop occurred. However, it didn't fall as low as previously and seems to be currently rising again. This is just one indicator among others, and it is unclear at this stage whether it is alarming or not. Other crisis indicators also range in medium levels, neither low nor high, making probable a scenario, in 2019, in which a sequence of severe corrections will occur, but no real krach, as we observed in 2008.

If such a scenario takes place, volatility will continue to wander between rather low levels and sudden peaks with a VIX exceeding 40 at several instances. The volatility over the year is likely to be above average.

To answer the third question, the yearly performance of the equity market depends on macroeconomic variables. In a context of high price/earnings ratios and low interest rates, with a Fed willing to put an end to Quantitative Easing and deteriorating trade relations with China, money will be more expensive, interest rates are likely to go up, while equities will concomitantly drop. The end of year performance will not only depend on the number and size of these corrections, but also on what happens in between, in a market driven by the data science revolution and the future of globalization. 
The alternative scenario by which markets recover with a low volatility is, in fact, not desirable. Indeed, it will reduce further the remuneration of capital, in a context of rising interest rates. This is a typical speculative bubble situation where only the hope of reselling assets at a higher price keeps their price so high. At some point, a downturn will happen. The stronger the disbalance on that day, the more severe the crisis.

\subsection{Scenario Analysis for 2019}

The economic outlook for 2019 is driven by a context of an overpriced stock market, with P/E ratios, despite the downturn since the end of September, remaining around 20. Interest rates, currently ranging between $2.5 \%$ and $3 \%$, from below $1.5 \%$ a couple of years ago, are still oriented positively, but could also drop back in case of a major crisis, upon a subsequent recession. In this post-quantitative easing situation, the market evolution in 2019 may take different shapes. Equities may rally again, supported by the artificial intelligence revolution and the success of "GAFA" companies and forthcoming unicorns. Interest rates, in this scenario, together with inflation, will rise at a moderate pace. If, on top, the Federal Reserve goes on reinforcing growth with a low rate policy, markets might rise even further in a potentially suicidal denial. On the contrary, if, upon an excessive interest rates surge, a sudden vanishing trust induces a massive crisis, in an amplitude similar to that of 2008, the flight to quality will bring back interest rates to very low levels again, while credit spreads will explode and defaults will happen in cascades. In our view, a more likely scenario lies in between these two extremes. A sequence of moderate corrections may occur, with or without recovery in between them. The volatility will remain rather high, due to this sequence of downturns, while interest rates will mildly rise or even stagnate. In such a scenario, some of the "BRIC" emerging markets (probably India, possibly Brazil, unlikely China and Russia) may appear as an alternative source of growth if the "GAFA" and other potential unicorns are delayed in their results or suffer from the geopolitical environment.

Let us list here the most probable scenarios for the year 2019. Portfolio design must account for all of them.

- Scenario 1: This is the optimistic scenario, by which the equity market appreciates over the year $(+15 \%)$, while interest rates remain at their low level $(\sim 3 \%)$ or slightly decrease. No major correction occurs, so the volatility is limited $(\sim 15 \%)$.

- Scenario 2: Although most discussions concerning 2019 range about the question of a major crisis, our preferred scenario is a sequence of limited corrections, aimed at bringing back $\mathrm{P} / \mathrm{E}$ ratios in a lower range, with some recovery in between, ending in a more or less neutral effect at the end of the year $(-2 \%)$, while interest rates rise moderately $(+1 \%)$. The volatility of the stock market rises accordingly $(\sim 25 \%)$.

- Scenario 3: The super-optimistic scenario corresponds to the continuation of the stock market rally $(+25 \%)$, while the Fed policy drives interest rates downwards $(\sim 1.5 \%)$. Volatility remains at a low level $(\sim 10 \%)$.

- Scenario 4: This scenario is similar to scenario 2, but with more severe corrections and no recovery in between. The stock market plummets $(-15 \%)$ while interest rates rise meaningfully $(+2 \%)$. The volatility reaches higher levels $(\sim 30 \%)$. Some emerging markets rally while others drop jointly with developed ones. 
- Scenario 5: This is the catastrophe scenario, experiencing a crisis of the same amplitude as that of $2008(-40 \%)$. Interest rates first rise importantly $(+3 \%)$, since a significant rise of interest rates is, in this scenario, at the origin of the crisis. Then they drop back upon the flight to quality. The volatility is extremely high in this case $(\sim 60 \%)$.

The two tables below - yearly performance and volatility - summarize and complete these hypotheses with emerging markets, which are sources of growth in good scenarios, but tend to suffer more than developed markets in case of crisis. The combined portfolio reproduces a typical allocation in such an uncertain environment (60\% fixed income, $40 \%$ equities).

\begin{tabular}{|r|l|r|r|r|r|r|}
\hline & Portfolio & $20 \%$ & $40 \%$ & $30 \%$ & $10 \%$ & \\
\hline Probability & & Cash & Bond & Equity & Emerging & Portfolio \\
\hline $30 \%$ & Scenario 1 & $2.0 \%$ & $5 \%$ & $15 \%$ & $25 \%$ & $9.25 \%$ \\
\hline $35 \%$ & Scenario 2 & $2.5 \%$ & $-2 \%$ & $-2 \%$ & $-10 \%$ & $-1.68 \%$ \\
\hline $10 \%$ & Scenario 3 & $2.0 \%$ & $15 \%$ & $25 \%$ & $40 \%$ & $17.25 \%$ \\
\hline $15 \%$ & Scenario 4 & $2.5 \%$ & $-10 \%$ & $-15 \%$ & $-15 \%$ & $-8.88 \%$ \\
\hline $10 \%$ & Scenario 5 & $1.5 \%$ & $0 \%$ & $-40 \%$ & $-70 \%$ & $-18.63 \%$ \\
\hline & Combined & $2.20 \%$ & $0.80 \%$ & $0.05 \%$ & $-1.25 \%$ & $0.72 \%$ \\
\hline
\end{tabular}

Table 1: Performance

\begin{tabular}{|l|r|r|r|r|r|r|}
\hline & \multicolumn{1}{|l|}{ Cash } & Bond & Equity & Emerging & Portfolio & Sharpe \\
\hline Scenario 1 & $0.10 \%$ & $5 \%$ & $15 \%$ & $25 \%$ & $11.78 \%$ & 0.79 \\
\hline Scenario 2 & $0.10 \%$ & $10 \%$ & $25 \%$ & $35 \%$ & $18.57 \%$ & -0.09 \\
\hline Scenario 3 & $0.10 \%$ & $5 \%$ & $10 \%$ & $25 \%$ & $10.06 \%$ & 1.71 \\
\hline Scenario 4 & $0.10 \%$ & $15 \%$ & $30 \%$ & $30 \%$ & $20.95 \%$ & -0.42 \\
\hline Scenario 5 & $0.10 \%$ & $25 \%$ & $60 \%$ & $100 \%$ & $47.95 \%$ & -0.39 \\
\hline Combined & $0.10 \%$ & $11.88 \%$ & $28.13 \%$ & $42.59 \%$ & $21.64 \%$ & 0.03 \\
\hline
\end{tabular}

Table 2: Volatility

The "combined" row is computed as the resulting expectation of a mixture of scenarios with probabilities indicated in Table 1. The positive or negative outcome of this estimation is highly dependent of the assumed probabilities, which are here only mentioned as a pure guess.

The following table displays the expected maximum drawdown (MDD) in each scenario, computed as a look-back put option with the above assumptions as expected return and volatility. Note that, as long as we assume that the worst scenario (\#5) has a probability greater than 5\%, the yearly $95 \%$ Value-at-Risk will be similar to the expected MDD in this scenario.

\begin{tabular}{|l|r|r|r|r|r|}
\hline & \multicolumn{1}{|c|}{ Cash } & \multicolumn{1}{c|}{ Bond } & \multicolumn{1}{l|}{ Equity } & \multicolumn{1}{c|}{ Emerging } & Portfolio \\
\hline Scenario 1 & $0.00 \%$ & $-2.14 \%$ & $-6.54 \%$ & $-11.03 \%$ & $-3.82 \%$ \\
\hline Scenario 2 & $0.00 \%$ & $-8.71 \%$ & $-19.27 \%$ & $-29.14 \%$ & $-11.74 \%$ \\
\hline Scenario 3 & $0.00 \%$ & $-0.89 \%$ & $-2.23 \%$ & $-8.55 \%$ & $-1.84 \%$ \\
\hline Scenario 4 & $0.00 \%$ & $-16.75 \%$ & $-28.68 \%$ & $-28.68 \%$ & $-17.33 \%$ \\
\hline Scenario 5 & $0.00 \%$ & $-18.44 \%$ & $-55.56 \%$ & $-80.43 \%$ & $-31.16 \%$ \\
\hline Combined & $0.00 \%$ & $-8.14 \%$ & $-18.79 \%$ & $-26.71 \%$ & $-11.16 \%$ \\
\hline
\end{tabular}


In these simulations, we haven't tried to optimize the portfolio, since the result highly depends on assumptions that can be the object of further discussions and/or studies. However, we have established the framework for portfolio allocation, based on sound risk and return analysis. One may include to these simulations other types of investment: real estate, alternatives, macro-hedge, etc. Whichever the type of assets, we strongly recommend this kind of scenario analysis. Indeed, analyses based on probability distributions, such as Markowitz, Black Litterman and consort, tend to considerably underestimate the probability and impact of "black swan" scenarios.

\section{Conclusion}

"Convexity is a zero-sum game" is probably the most provocative sentence of this article, but also that which best summarizes it. Whereas putting in place a trading strategy that produces a "convex" reaction to market shifts is rather sound a practice for the marginal manager, once it reaches a significant portion of the bulk of the market, convexity induces dynamic instabilities that require utmost attention. Market dynamics are essentially driven by trends, bubbles, fears, overreactions and, most of all, herd behavior. At the system level, only a long-lasting Darwinian natural selection process produces robust antifragility. We have seen, in this article, how artificially created convexity (the core ingredient of antifragility) implies dynamic instability as soon as its implementation is mechanical and myopic, in the sense that the feedback loop between market observation and trading action only involves short observation periods. This appears as a severe concern at a time where more and more dynamically traded ETFs (whether active or purely quantitative) are being proposed to institutional investors.

The solution to a safer implementation of antifragility, stabilizing markets rather than destabilizing them, while not biasing the natural evolution of the economy, relies on the dispersion of portfolio managers reactions to market evolution. Paradoxically, the more complex and proprietary the rules and algorithms employed by managers, the less "herdy" their actions, hence the less unstable dynamics occur. Avenues have been proposed here to anticipate financial crises and tame down their impact on portfolios managed for the long-term.

Portfolio construction based on short-term myopic distributional estimates tend to underestimate the contribution of extreme scenarios to the overall expectation. Even worse, the consequence of naïve optimization is to increase even further this contribution. We showed how to implement a sound scenario analysis in order to properly take into account both optimistic situations and black swans. Such an analysis strongly depends on assumptions about the size and probabilities of these scenarios, but, overall, it provides a much less biased analysis and is not lured by erroneous statistics, like supposedly “optimized" portfolios. 


\section{References}

Black, F., \& Litterman, R. B. (1991, September). Asset Allocation Combining Investor Views with Market Equilibrium. The Journal of Fixed Income, 1(2), pp. 7-18.

Bollerslev, T. (1986). Generalized Autoregressive Conditional Heteroskedasticity. Journal of Econometrics, 31(3), pp. 307-327.

Coste, C., Douady, R., \& Zovko, I. (2011). The Stress VaR: A New Risk Concept for Extreme Risk and Fund Allocation. Journal of Alternative Investments, 13(3), pp. 10-23.

Douady, R. (2017, October 9). Dominant Factor Analysis by Nonlinear Polymodels. Retrieved from MCFAM Distinguished Lectures, University of Minnesota: https://math.umn.edu/sites/math.umn.edu/files/dominant_factor_analysis_by_polymodels.pdf

Douady, R., \& Kornprobst, A. (2018). An Empirical Approach to Financial Crisis Indicators Based on Random Matrices. Intl. Jour. of Theo. and App. Finance, 21(3), pp. 1-122.

Douady, R., \& Ye, X. (2019). Systemic Risk Indicators Based on Nonlinear PolyModel. J. Risk Financial Manag., 12(2), pp. 1-24.

Engle, R. F. (1982). Autoregressive Conditional Heteroscedasticity with Estimates of the Variance of United Kingdom Inflation. Econometrica, 50(4), pp. 987-1007.

Fama, E. (1965). The Behavior of Stock Market Prices. Journal of Business, 38, pp. 34-105.

Hommes, C. H. (2006). Heterogeneous Agent Models in Economics and Finance. In L. Tesfatsion, \& K. L. Judd, Handbook of computational economics, Vol 2, Agent-Based Computational Economics. Amsterdam: North-Holland.

Kelly, J. L. (1956). A New Interpretation of Information Rate. Bell System Technical Journal, 35(4), pp. 917-926.

Khandani, A., \& Lo, A. (2007, November). What happened to the quants in August 2007. MIT working paper.

Kindleberger, C. P., \& Aliber, R. (1978). Manias, Panics, and Crashes: A History of Financial Crises (1st ed.). Basic Books.

Kindleberger, C. P., \& Aliber, R. (2015). Manias, Panics, and Crashes: A History of Financial Crises (7th ed.). Palgrave MacMillan.

Knight, F. H. (1921). Risk, Uncertainty, and Profit. Boston, MA: Hart, Schaffner \& Marx; Houghton Mifflin Company.

Mandelbrot, B. (1963). The Variation of Certain Speculative Prices. The Journal of Business, 36, p. 394.

Marchenko, V. A., \& Pastur, L. А. (1967). Распределение собственных значений в некоторых ансамблях случайных матриц (Distribution of eigenvalues for some sets of random matrices). Mat. Sb. N.S. (in Russian), 72(114:4), pp. 507-536.

Markowitz, H. M. (1959). Portfolio Selection: Efficient Diversification of Investments (1st ed.). New York: John Wiley \& Sons. 
Markowitz, H. M. (1991). Portfolio Selection: Efficient Diversification of Investments (2nd ed.). Basil Blackwell.

Minsky, H. (1992). The Financial Instability Hypothesis. Levy Economic Institute of Bard College Working Paper, 74, pp. 6-8.

Minsky, H. P. (1986). Stabilizing an Unstable Economy. Bard College Paper, Hyman P. Minsky Archive, 144.

Peters, E. (1994). Fractal Market Analysis: Applying Chaos Theory to Investment and Economics. New York: John Wiley \& Sons.

Rubinstein, M., \& Leyland, H. (1981, July-August). Replicating Options with Positions in Stocks and Cash. Financial Analysts Journal, 37(4), pp. 63-72.

Sharpe, W. F. (1966). Mutual Fund Performance. Journal of Business, 39(S1), pp. 119-138.

Sornette, D., \& Cauwells, P. (2015). Financial Bubbles: Mechanisms and Diagnostics. Review of Behavioral Economics, 2(3), pp. 279-305.

Taleb, N. N. (2000). The Black Swan. Random House.

Taleb, N. N. (2012). Antifragile: Things That Gain from Disorder. Random House.

Taleb, N. N., \& Douady, R. (2013). Mathematical definition, mapping, and detection of (anti)fragility. Quantitative Finance, 13(11), pp. 1677-1689.

Tefsatsion, L., \& Judd, K. L. (2006). Handbook of computational economics, Vol 2, Agent-Based Computational Economics. Amsterdam: North Holland.

Wikipedia. (2003). Black Monday (1987). Retrieved from https://en.wikipedia.org/wiki/Black_Monday_(1987) 